\title{
EL DISTRITO GUBERNAMENTAL DE LA CIUDAD DE BUENOS AIRES. EL DINÁMICO VÍNCULO ENTRE LA POLÍTICA, EL CONFLICTO Y EL LITIGIO JUDICIAL ${ }^{1}$
}

\section{THE GOVERNMENTAL DISTRICT OF THE CITY OF BUENOS AIRES. THE DYNAMIC LINK BETWEEN POLITICS, CONFLICT AND LITIGATION}

\section{Carolina María Gonzalez Redondo²}

\section{Resumen}

Este artículo reflexiona sobre las articulaciones que se producen entre el procesamiento de una política urbana, el conflicto suscitado a partir de su implementación y el litigio judicial, en tanto que una de sus dimensiones. Para ello, analiza el proceso de judicialización de un conflicto generado a partir del proyecto de construcción de un centro cívico en un predio -ubicado en la zona sur de la ciudad de Buenos Aires- destinado a la atención de la salud mental. A partir de una estrategia metodológica cualitativa que incorpora el análisis discursivo de documentos jurídicos, se da cuenta de las sucesivas (re)elaboraciones del conflicto cuando ingresa al campo del derecho. Asimismo, se explora cómo las relaciones de poder y las agendas propias de los operadores jurídicos han contribuido en esta redefinición y, por tanto, en el desarrollo del conflicto. Por último, se indaga sobre los efectos de las decisiones judiciales en el procesamiento de la política pública, pero también sobre el modo en que el curso de acción de esta última fue influyendo en el desarrollo del litigio judicial. Así, el análisis de la judicialización de un conflicto por los usos de un espacio urbano invita a complejizar la mirada sobre el rol del Estado en el procesamiento de una política pública, considerando los tres poderes que lo conforman y las tensiones entre ellos.

Palabras clave: judicialización, conflicto urbano, políticas públicas, análisis del discurso, distrito gubernamental.

\footnotetext{
1 Este artículo recupera parte de los hallazgos producidos en el marco de mi tesis de maestría denominada *anonimizado*.

2 E-mail: carito_gr@yahoo.com.ar
} 


\section{Abstract}

This paper reflects on the linkages between an urban policy, the conflict that arose from its implementation and the litigation, conceived as one of its dimensions. To this end this article analyses the judicialisation of a conflict that arose from the government's intention of building a civic center in a site -located in the south of Buenos Aires city-occupied by three mental health hospitals. Through a qualitative approach that includes the discourse analysis of legal documents, this paper looks into the successive (re)elaboration of the conflict once it becomes a part of the judicial field. In the same way, this work explores how the power relations and the own agendas of legal practitioners contributes to this redefinition. Finally, it delves into the effects of judicial decisions in the development of the public policy, but also gives attentions to the way in which the course of action of the policy influences the judicial process. Thus, this study about the judicialisation of a conflict related to the uses of urban space enables more complex analysis about the role of the three powers of the State regarding the implementation of public policies.

Keywords: judicialization, urban conflict, public policies, discourse analysis, civic center. 


\section{INTRODUCCIÓN}

Este artículo busca reflexionar sobre las complejas articulaciones que se producen entre el procesamiento de una política urbana, el conflicto derivado a partir de ella y su judicialización, entendida como una de las arenas por las que transita una controversia. Para ello, analizamos el proceso de judicialización del conflicto suscitado a raíz del proyecto de construcción de un centro cívico en un predio -ubicado en la zona sur de la ciudad de Buenos Aires- donde funcionan tres hospitales públicos de atención a la salud mental.

El análisis de este caso nos permite indagar sobre los efectos de las decisiones judiciales en el procesamiento de la política pública, pero también sobre el modo en que el curso de acción de esta última fue influyendo en el desarrollo del litigio judicial. Asimismo nos preguntamos por el rol de los operadores jurídicos en la redefinición del conflicto; concebidos estos últimos como aquellos sujetos que intervienen directamente en el campo jurídico -jueces, magistrados, defensores, fiscales, abogados, procuradores, agentes judiciales- y que, en tanto actores sociales inmersos en una red de relaciones sociales, no son ajenos a los procesos sociales en los que se desarrolla su acción (Cuellar, 2014). Para ello, combinamos una perspectiva de análisis de políticas públicas con las propuestas derivadas de una serie de trabajos recientes orientados a complejizar la mirada sobre el derecho y los efectos sociales de las decisiones judiciales ${ }^{3}$.

Nos apoyamos en una estrategia cualitativa que incluye el análisis de entrevistas a actores involucrados en el conflicto, documentos normativos, resoluciones y sentencias judiciales. Cabe señalar que un aporte importante de este trabajo es el abordaje de un corpus de expedientes judiciales desde un dispositivo para el análisis de los discursos -elaborado ad hoc- que nos permitió, por un lado, problematizar el carácter constituyente del discurso jurídico $y$, por el otro, dar cuenta de las sucesivas redefiniciones del conflicto cuando ingresa al campo del derecho.

Para nuestro análisis, retomamos la definición de política pública desarrollada por Oszlak y O'Donnell (1981) concebida como un conjunto de acciones y omisiones que manifiestan la intervención de diversos actores, entre ellos el Estado, que se movilizan en torno a una cuestión, entendida esta última como un asunto socialmente problematizado. El modo en que el Estado -y también los otros actores- se involucra en el procesamiento de las cuestiones

\footnotetext{
${ }^{3}$ Véase Azuela y Cancino (2014) y el dossier "A judicialização dos conflitos urbano-ambientais na América Latina" de la Revista Direito e práxis, Vol. 14, 2016. 7, n 14, 2016.
} 
implica sucesivas tomas de posición, que no son homogéneas, ni constantes a lo largo de todo el proceso de la política pública, desde la problematización de la cuestión hasta su resolución (Oszlak y O'Donnell, 1981). Aquí consideramos como actores sólo aquellos que toman posición para incidir en la cuestión (Oszlak, 2011). Así, estas tomas de posición dan cuenta de una estrategia de acción que se apoya en su dotación relativa de recursos de poder y en las expectativas de comportamiento de otros actores.

El estudio de las políticas públicas desde esta perspectiva nos permite analizar al "Estado en acción", deteniéndonos en sus prácticas, modos de hacer y gestionar. Se trata de un Estado "desagregado y descongelado como estructura global y puesto en un proceso social en el que se entrecruza complejamente con otras fuerzas sociales" (Oszlak y O’Donnell, 1981: 99). Desde una mirada materialista, la sociedad está envuelta en una contradicción irresoluble, atravesada por antagonismos irreconciliables, y aun cuando el Estado se sitúe aparentemente por fuera de ella para moderar y dirimir esos conflictos, éstos permean sus instituciones y sus prácticas (Harvey, 1970). Así el Estado es una relación de fuerzas y, por tanto, su derecho y sus instituciones están atravesadas por las contradicciones de la sociedad (O'Donnell, 1984). El Estado, "cosificado en sus instituciones, es la máscara de la sociedad, apariencia de fuerza externa movida por una racionalidad superior que se muestra (y se cree) encarnación de un orden justo al que sirve como árbitro neutral” (O’Donnell, 1984: 225). Entre las instituciones del Estado moderno, el poder judicial es quien encarna ese supuesto árbitro neutral amparado en el derecho racional-formal que surge y se expande juntamente con el sistema capitalista y, como tal, no está exento de ambigüedades.

El análisis de las sucesivas (re)definiciones del conflicto cuando ingresa al campo del derecho (Azuela, 2014) permite advertir cómo se ponen de manifiesto las ambigüedades que atraviesan al poder judicial. Como veremos más adelante, el derecho es dinámico e indeterminado (Azuela y Melé, 2005), y esto habilita interpretaciones y lecturas contrapuestas por parte de los operadores jurídicos. Siguiendo a Azuela (2014), cuando los actores Ilevan sus conflictos al mundo del derecho activan las relaciones de poder entre los órganos del Estado.

Cada vez que un juez de amparo tiene que resolver sobre la constitucionalidad de un acto de autoridad, está redefiniendo la relación del poder judicial con la administración; no importa qué tan independiente quiera ser, esa independencia se vuelve parte del conflicto (Azuela, 2014: 25).

En este sentido, indagar sobre la judicialización del conflicto generado a raíz del proyecto del centro cívico nos permitirá complejizar nuestra mirada sobre el rol del Estado en el 
procesamiento de la política, considerando los tres poderes que lo conforman y las tensiones entre ellos.

Dividimos este artículo en cinco apartados. En el primero, recuperamos algunas cuestiones metodológicas y reflexionamos sobre el corpus de documentos que analizamos en este trabajo. Luego, reconstruimos brevemente la política del distrito gubernamental y cómo ésta se convierte en un conflicto por el uso de un espacio urbano. En el tercer apartado, presentamos las distintas demandas que introducen el conflicto en el campo jurídico, focalizando en las sucesivas (re)definiciones del conflicto en el transcurso del litigio. En relación con esto, en el cuarto apartado, exploramos cómo las relaciones de poder y las agendas propias de los operadores jurídicos han contribuido en esta redefinición y, por tanto, en el desarrollo del conflicto. En el último apartado, indagamos sobre los efectos producidos por las distintas decisiones judiciales, cómo éstas fueron moldeando el curso de acción de esta política urbana, llevando el compás del conflicto. Pero también analizamos cómo las otras estrategias de los actores incidieron en el desarrollo del litigio, obligando a los operadores jurídicos a actuar y dictar nuevas sentencias. Cerramos con un apartado final en el que presentamos las principales conclusiones del trabajo.

\section{EL ABORDAJE TEÓRICO-METODOLÓGICO DEL DISCURSO JUDICIAL COMO DISCURSO CONSTITUYENTE}

Parte importante de este trabajo se basa en el análisis discursivo de un corpus conformado por once documentos jurídicos que incluyen fallos de primera y segunda instancia del fuero Contencioso Administrativo y Tributario (CAyT) de la ciudad de Buenos Aires; sentencias del Tribunal Superior de Justicia (TSJ); y las demandas formuladas por los actores a través de sus representantes jurídicos ${ }^{4}$. Para su abordaje, construimos un dispositivo para el análisis de los discursos que, siguiendo la perspectiva teórica de la escuela francesa, combina

\footnotetext{
${ }^{4}$ Acción de amparo colectivo en la causa "Naddeo, María Elena y otros contra GCBA sobre amparo (art. 14 CCABA), expte. №45.258, agosto de 2012; Juzgado de primera instancia en lo CAyT №5, expte №45.258, resolución del 05/09/2012 [MP Fabiana Schafrik]; Juzgado de primera instancia en lo CAyT №2, expte. №45.995, resolución del 27/10/2012, [MP Patricia Lopez de Vergara]; Cámara de Apelaciones en lo CAyT, Sala II, expte. №45.995, resolución del 28/12/2012; Juzgado de feria de primera instancia en lo CAyT, expte. G17-2013/1, resolución del 16/01/2013 [MP Elena Liberatori]; Juzgado de primera instancia en lo CAyT №9, expte. 45.258, resolución del 19/02/2013 [MP Andrea Danas]; Cámara de Apelaciones en lo CAyT, Sala II, expte №G17-2013/1, resolución del 26/04/2013; Cámara de Apelaciones en lo CAyT, Sala II, exptes. №45.258, №45.995, №G17-2013/1, resolución del 19/09/2013; TSJ, expte. G17-2013/1, resolución del 16/12/2015.
} 
elementos de las teorías de la enunciación y de la argumentación ${ }^{5}$. Por un lado, el análisis de ciertos recursos lingüísticos y estrategias enunciativas -como el uso de los tiempos y modos verbales, los deícticos, apelativos, subjetivemas y modalidades- nos permite identificar efectos de sentido y el tono y el cuerpo -el ethos ${ }^{6}$ - que construye el enunciador a lo largo del enunciado. Por el otro, el análisis de las estrategias argumentativas -el despliegue de topos retóricos y lugares comunes (Amossy, 2000)- nos ayuda a deconstruir las tematizaciones sobre el espacio disputado y sobre el conflicto en los distintos documentos. Así, nuestro análisis se asienta en el nivel intradiscursivo -ese plano en el que se sitúan las operaciones enunciativas y argumentativas, donde el sujeto-enunciador aparece incorporando de distintos modos las voces ajenas, administrando la polifonía (Montero, 2014)-, pero teniendo como horizonte su vínculo con el interdiscurso, ese nivel constitutivo en el que el sujeto es hablado por el discurso, es un sujeto del inconsciente atrapado por las formaciones discursivas e ideológicas ${ }^{7}$.

Este abordaje nos permitió acercarnos a los argumentos puestos en juego por los operadores jurídicos en las distintas demandas y sentencias; y al modo en que fueron (re)definidos, tematizados -cada vez- el conflicto y el espacio disputado. Advertimos que la

\footnotetext{
${ }^{5}$ Los primeros trabajos de la escuela francesa de análisis del discurso estuvieron muy vinculados al concepto de ideología elaborado por el filósofo marxista Louis Althusser (1970). Así predominó un esfuerzo por articular las teorías del discurso, la ideología y el psicoanálisis, con Pecheux como gran exponente (Charaudeau y Maingueneau, 2002). Hacia fines de la década del '70, y en sintonía con los cambios de la época, se producen algunas reformulaciones teóricas y metodológicas importantes (Maldidier, 1990) que hacen que el foco de estudio de la escuela francesa se traslade hacia la enunciación y, posteriormente, a la argumentación (Montero, 2014). Lo interesante de esta perspectiva es que invita a pensar en la dimensión conflictiva que constituye todo discurso en tanto que su sentido no es unívoco, existe una lucha por su fijación. No hay una "democracia discursiva", no cualquier voz es legítima en cualquier momento y lugar. Tal como sostiene Angenot (1989), las tematizaciones no son aleatorias, sino que responden a tendencias hegemónicas y leyes tácitas que regulan lo posible de ser dicho en un momento dado.

${ }^{6}$ Siguiendo a Maingueneau (1996), todo discurso posee una vocalidad que se manifiesta a través de un tono e implica una determinación de un cuerpo del enunciador, es el ethos que se va construyendo a lo largo del enunciado. Ese ethos juega el papel de garante de la enunciación, garante al que se le atribuye un carácter y una corporalidad que se apoyan en representaciones sociales valorizadas o desvalorizadas. La identificación del ethos asociado al enunciador permite advertir el posicionamiento del enunciador, el lugar social desde el que habla, el enunciatario que construye y los qué ámbitos institucionales que legitiman su enunciado, en asociación con una determinada formación discursiva (Foucault, 1969).

${ }^{7}$ Acuñado por Foucault (1969) y reformulado por Pecheux (1971), el concepto de formación discursiva hace referencia a "lo posible de ser dicho desde una posición dada en una coyuntura dada" (Pecheux, 1971 citado en Maldidier, 1990: 206). Según este autor, las formaciones discursivas son la forma material y discursiva de las formaciones ideológicas - "conjunto complejo de actitudes y representaciones que no son ni individuales ni universales, pero remiten más o menos directamente a posiciones de clase en conflicto" (Pecheux, 1990: 102, citado en Montero, 2014). Las formaciones ideológicas están habitadas por el conflicto y se componen de una o muchas formaciones discursivas. Las palabras cambian de sentido al pasar de una formación discursiva a otra. Y la formación discursiva sólo se mantiene y se constituye a través del interdiscurso (Maingueneau, 1996).
} 
disputa por la tematización de este último es central a lo largo del litigio. El modo en que es definido este espacio habilita la invocación de diversos derechos lesionados que se tornan argumentos productivos en la controversia judicial, dando lugar (o no) a la introducción de distintas herramientas procesales vinculadas a la legitimidad de los actores, a la urgencia del caso y al interés público puesto en juego.

Siguiendo a Maingueneau y Cossutta (1995), el discurso jurídico es parte de los discursos constituyentes, concebidos como aquellos que tienen un papel fundador, es decir, que se presentan como los "garantes últimos de la multiplicidad de producciones discursivas de una colectividad" (Maingueneau, 1996: 28). Este tipo de discursos se autorizan a ellos mismos, lo que dota de un carácter particular a sus enunciados, que son también cargados de autoridad:

Una de las características de los enunciados que pertenecen a los DC es estar a la vez más o menos cerrados sobre su organización interna y ser reinscribibles en otros discursos. (...) Así, una obra constituyente juega su papel no solamente por los contenidos que vehiculiza sino también por los modos de enunciación que autoriza (Maingueneau y Cosutta, 1995: 6).

Este lugar de autoridad, la función de archéion, se construye en y por el discurso, definiendo un lugar de enunciadores consagrados y la elaboración de una memoria (Maingueneau y Cosutta, 1995). Pero no sólo se autorizan a ellos mismos, son autoconstituyentes, sino que también juegan un papel constituyente para otros discursos, en este sentido, son heteroconstituyentes. Asimismo, como todo discurso, está dominado por una formación discursiva específica, en este caso ligada al campo del derecho, con sus propias reglas de formación y sus regularidades que moldean sus condiciones de emergencia y de funcionamiento enunciativo.

El repaso de las operaciones enunciativas que identificamos en los fallos judiciales que conforman nuestro corpus, es decir, el modo en que se construye a sí mismo el enunciador con qué ethos se asocia- y qué enunciatario configura nos permite acercarnos mejor a este carácter constituyente del discurso jurídico. Esto es así porque en los discursos constituyentes las formas enunciativas no sólo son un vector de ideas, sino que además

representan la institución en el discurso al mismo tiempo que legitiman (o deslegitiman) el universo social donde vienen a inscribirse. Hay constitución precisamente en la medida en la que un dispositivo enunciativo funda, de algún modo performativo, su propia posibilidad, haciéndolo como si obtuviera esa legitimidad de una fuente que no haría más que encarnar (el Verbo revelado, la Razón, la Ley...). Hay así una circularidad constitutiva entre la imagen que deja ver de su propia instauración y la validación retrospectiva de una cierta configuración de redes de comunicación, de difusión de los saberes, de repartición de la 
autoridad, de ejercicio del poder que garantiza, denuncia o promueve por su gesto instaurador (Maingueneau y Cosutta, 1995: 9).

En las demandas y fallos que aquí analizamos, y fundamentalmente en estos últimos, esta circularidad constitutiva se torna evidente en el entramado de legitimación y de validación construido: los argumentos desplegados invocan como garante, como fuente de legitimidad, la Ley (ya sea internacional, nacional o local), la jurisprudencia (es decir, otros enunciados que forman parte de esta comunidad discursiva y que conforman su memoria) y la doctrina (producida por el conjunto de enunciadores consagrados), todos ellos enunciados internos al discurso jurídico y al propio sistema judicial, de ahí que se autorice a sí mismo.

Las sentencias analizadas comparten una organización textual rígida; aspectos estilísticos y composicionales; y recursos lingüísticos específicos, propios del género. En un primer apartado "autos y vistos" o "considerandos" se presentan los antecedentes del expediente, que incluyen los argumentos elaborados por las distintas partes (actores y demandados), produciendo siempre un efecto de distanciamiento sobre esos discursos. Este efecto se advierte en el uso de la cita directa, o la indirecta marcada por verbos en pasado o presente simple, en modo indicativo, y empleados en la tercera personal del singular o del plural ("relatan", "indican", "señalan", "denuncian", "interpretan”). Este tipo de organización textual, en el que primero se retoman los argumentos de "todas las partes" para luego "analizar" y "decidir", produce un efecto de imparcialidad, de objetividad, que refuerza el rol de árbitro neutral que asume el enunciador: "La demandada se inclina por la negativa, la Sra. Defensora (...) en sentido contrario, quedando pues, en cabeza de este tribunal la dilucidación" ${ }^{\prime 8}$.

Luego de presentar los argumentos de "ambas partes", los jueces (en forma individual o grupal, cuando se trata de un tribunal) "analizan" los hechos y los argumentos; señalando la "documentación acompañada" y dando cuenta del "sustento normativo". En esta parte de "análisis", predomina el uso del impersonal, del modo indicativo y de pasivaciones. Esto, sumado al empleo de verbos como "acreditar" y "evidenciar", colaboran en la creación de un efecto de sentido de objetividad, borrando las huellas del enunciador. Todo ello es reforzado por el reenvío a otras fuentes de legitimidad, como dijimos previamente, las leyes, la jurisprudencia y la doctrina; y por el empleo de un vocabulario técnico y formal.

\footnotetext{
8 Juzgado de primera instancia en lo CAyT №9, expte. 45.258, resolución del 19/02/2013 [MP Andrea Danas], pp. 29.
} 
Con excepción de dos fallos ${ }^{9}$ en los que por momentos se hace uso de la primera persona, la fórmula final donde se explicita la sentencia, suele expresarse con el uso del impersonal ("se resuelve"), o en tercera persona ("el tribunal resuelve"), de modo que el enunciador se distancia, no se responsabiliza por la decisión.

La organización textual, los recursos lingüísticos y gramaticales, y el vocabulario técnico, propio de la jerga judicial, que incluye, por ejemplo, expresiones en latín, permiten advertir la construcción de un enunciador asociado a un ethos de experto, que conoce las reglas del campo. En algunos casos el empleo de verbos como "examinar" y "verificar" configura además un enunciador asociado a un ethos de árbitro, asumiendo el rol de autoridad legitimada para llevar a cabo esas acciones. Del otro lado, se prefigura un enunciatario par (otros operadores jurídicos), que tiene las competencias y conocimientos necesarios para comprender estos enunciados.

\section{DE LA POLÍTICA AL CONFLICTO POR LOS USOS DE UN ESPACIO URBANO}

Desde el año 2008, el Gobierno de la Ciudad de Buenos Aires (GCBA) lleva adelante una política de creación de distritos especializados, mediante la cual se promueve la radicación de empresas e instituciones de un mismo sector económico en áreas específicas de la ciudad, a través de beneficios impositivos, créditos a tasa subsidiada y la creación de infraestructura, entre otras cosas. En la actualidad existen cinco distritos de desarrollo económico (DDE) (mapa 1): el Distrito Tecnológico Parque Patricios (DTPP, ley 2972/08), el Distrito Audiovisual (DAu, ley 3876/11), el Distrito de las Artes en La Boca (DA, ley 4.353/12), el Distrito del Diseño en Barracas (DDi, ley 4761/13), y el Distrito del Deporte en Villa Soldati y Lugano (DDe, ley 5235/14). Con excepción del DAu, todos los distritos se emplazan en barrios de la zona sur de la ciudad. Junto con una cantidad de iniciativas de desarrollo urbano público-privadas ${ }^{10}$, estos distritos son presentados por la actual gestión del GCBA como una respuesta al histórico desequilibro entre una zona norte pujante y un área sur deteriorada y, a la vez, como una

\footnotetext{
9 Juzgado de feria de primera instancia en lo CAyT, expte. G17-2013/1, resolución del 16/01/2013 [MP Elena Liberatori] y Juzgado de primera instancia en lo CAyT №9, expte. 45.258, resolución del 19/02/2013 [MP Andrea Danas].

${ }^{10}$ La construcción de institutos terciarios de la Universidad de Buenos Aires (UBA), la extensión de la línea $\mathrm{H}$ del subte, la creación de líneas de Metrobus, la inauguración del predio para recitales "Ciudad Rock", entre otros. Ver nota de prensa del GCBA, "Acciones para el crecimiento de los barrios del Sur", 06/08/2015. Disponible en http://www.buenosaires.gob.ar/noticias/el-sur-prioridad-estrategica (Captura: 05/02/2016)
} 
oportunidad para mejorar la inserción de Buenos Aires en la economía global. Asimismo, al desarrollarse de manera sistemática, estos distritos rompen con la lógica fragmentaria de las intervenciones urbanas precedentes (Goicoechea, 2016), a la vez que profundizan y amplían una serie de políticas de renovación urbana ${ }^{11}$ llevadas a cabo en la zona sur de la ciudad desde fines de $\operatorname{los}^{\prime} 80^{12}$.

Mapa 1: Ubicación de los distritos especializados y de las nuevas sedes de gobierno.

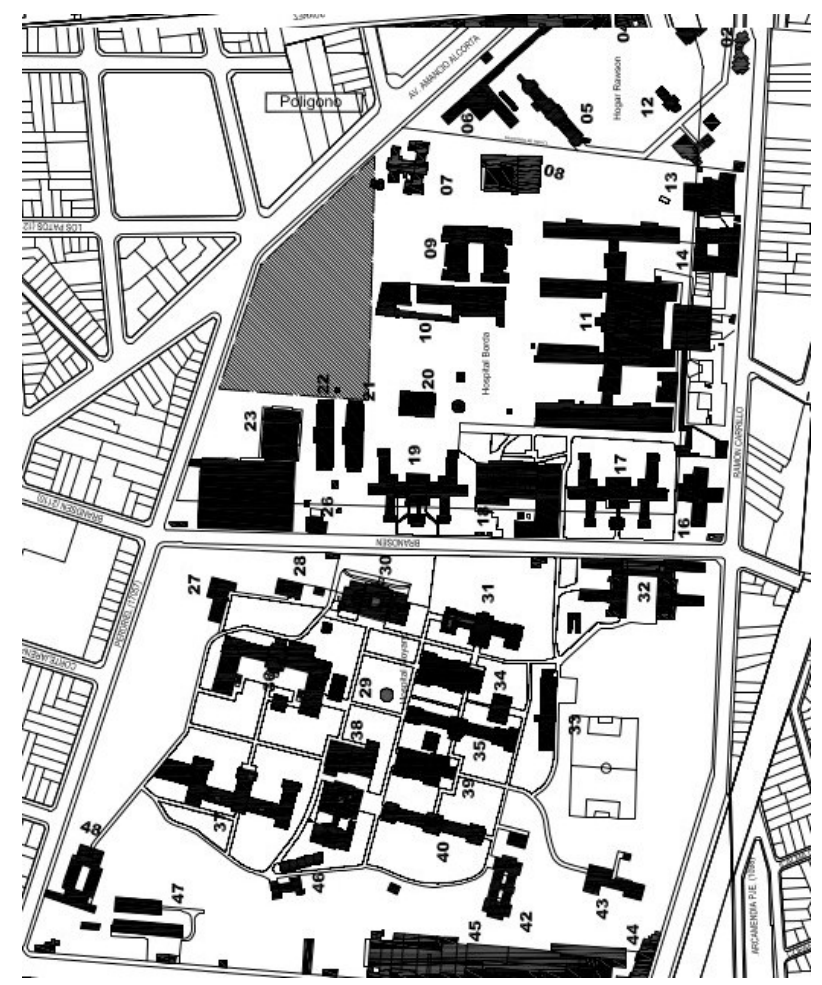

Fuente: elaboración propia en base a información del GCBA.

\footnotetext{
${ }^{11}$ Entendidas como aquellas intervenciones orientadas a la transformación y mejora del entorno físico y urbanístico de una zona (Diaz Parra, 2013; Rodríguez, 2015) que, al llevarse a cabo en "espacios gentrificables" (Diaz Parra, 2004), pueden detonar procesos de gentrificación. Estos últimos son concebidos como procesos ligados al sistema de estratificación social (Herzer, 2008) que implican el reemplazo de una población de clase trabajadora por clases medias y medias altas (Rodríguez, 2015). Así, la renovación alude a la puesta en valor de zonas degradadas de la ciudad apelando a recursos escenográficos vinculados a la cultura, el patrimonio, la naturaleza, la tradición, estética, diseño, etc, pero sin que como contracara se produzca obligadamente un fenómeno de desplazamiento, es decir de gentrificación, aunque éste sea uno de los efectos posibles.

${ }_{12}$ Desde la autonomización política de la ciudad, en el año 1996, las políticas hacia el sur se orientaron a "incorporar el sur al norte" (Rodriguez y Di Virgilio, 2014), conduciendo el Estado un proceso activo de renovación urbana que tiene su correlato en la progresiva concentración del gasto público en esta área de la ciudad, particularmente en las comunas 4 y 8 (Di Virgilio y Guevara, 2014; Guevara, 2010; Rodríguez, Bañuelos y Mera, 2008). Las políticas de renovación estuvieron primero concentradas en las zonas más cercanas al microcentro porteño, luego se fueron extendiendo hacia el sudeste, abarcando los barrios de La Boca y Barracas y, más recientemente, han llegado a los barrios de la comuna 8 (barrios de Villa Soldati, Villa Lugano y Villa Riachuelo), pasando previamente por Parque Patricios.
} 
El distrito gubernamental o centro cívico ${ }^{13}$ se inscribe en esta política de distritos especializados, aunque tiene la particularidad de buscar la relocalización del sector público (en lugar de empresas privadas), en un contexto barrial donde se están impulsando otras iniciativas de revalorización del espacio urbano. El proceso de renovación de esta zona de la ciudad y la obligación de reconvertir el sistema de salud mental ${ }^{14}$ constituyen la condición de posibilidad para la radicación del distrito gubernamental en el predio donde actualmente funcionan los hospitales psicoasistenciales Borda, Moyano y Tobar García, entre otras instituciones (mapa 1) (*anonimizado*). Las nuevas normativas nacional y local sobre salud mental obligan a todas las jurisdicciones del país a sustituir los hospitales neuropsiquiátricos por dispositivos comunitarios adecuados a los principios de la ley para el año 2020. Utilizando esto como principal argumento, desde el año 2008 el GCBA impulsa el cierre de estos hospitales y la refuncionalización de las casi 40 hectáreas que los albergan para la realización de un nuevo centro administrativo, terciario y comercial donde se concentren todas las funciones del gobierno local. Al igual que los distritos económicos, el centro cívico es además presentado por el GCBA como un proyecto que apunta al "desarrollo" de un barrio y un espacio "deteriorados" (*anonimizado*).

El proyecto inicial, denominado Parque Cívico, en su versión completa, no avanzó más allá de la instancia proyectual (imagen 1). Sin embargo, en 2012 el GCBA llamó a concurso y licitó la construcción de los Nuevos Edificios del Distrito Gubernamental, que constituyen la fase I del proyecto del Parque Cívico. Estos edificios serían construidos en una parte de aquel predio, dentro del Hospital Borda (imagen 2), donde funcionaba el taller protegido 19 -en el que se realizaban actividades de resocialización a través de la formación en oficios- y donde aún hoy permanece una cancha de fútbol que utilizan los pacientes. Es precisamente este espacio el que

${ }^{13}$ En relación a los distintos nombres que se le dieron a esta política, cabe aquí aclarar que -en este trabajo- utilizamos alternadamente las denominaciones "distrito gubernamental" o "centro cívico" como sinónimos; mientras que con "Parque Cívico" nos referimos al primer antecedente del proyecto del año 2008 y reservamos el término "nueva sede de gobierno" para aludir a las nuevas oficinas del GCBA situadas en Parque Patricios y en La Boca.

${ }^{14}$ Las nuevas leyes de salud mental de la nación ( $\left.\mathrm{N}^{\circ} 26.657 / 10\right)$ y de la ciudad ( $\left.\mathrm{N}^{\circ} 448 / 00\right)$ promueven un cambio de paradigma con respecto a la concepción sobre la salud mental, la forma de atenderla y el paciente, quien es considerado como un sujeto de derechos, con especial énfasis en los derechos humanos. Ambas leyes apuntan a un pasaje de un modelo hospitalocéntrico a un nuevo modelo de salud mental que privilegie prácticas ambulatorias, procurando la conservación de los vínculos sociales, familiares y la reinserción social y laboral de los pacientes. Este cambio de paradigma, denominado proceso de desmanicomialización, es objeto de debate en el ámbito de la salud mental a nivel internacional, nacional y local. Si bien la obligación de sustituir los hospitales monovalentes es uno de los argumentos que esgrime el GCBA para la creación del distrito gubernamental, existen informes de diversas organizaciones sociales, gremiales y de la Legislatura porteña que denuncian el incumplimiento de ambas leyes y la falta de creación de los dispositivos alternativos sustituyan a los hospitales en cuestión (Comisión Especial de Seguimiento de la Ley №448 de Salud Mental, 2010, 2012 y 2014-2015). 
se vuelve objeto de disputa entre distintos actores, fundamentalmente algunas dependencias del GCBA, y parte de los trabajadores del hospital y de Talleres Protegidos ${ }^{15}$, acompañados por legisladores de partidos de la oposición y organizaciones sociales.

Imágenes 1 (izq.) y 2 (der.): Diseño del Parque Cívico según la propuesta ganadora del concurso de 2008 (izq.). Plano de localización del área destinada a la primera etapa del distrito gubernamental, zona grisada (der.)

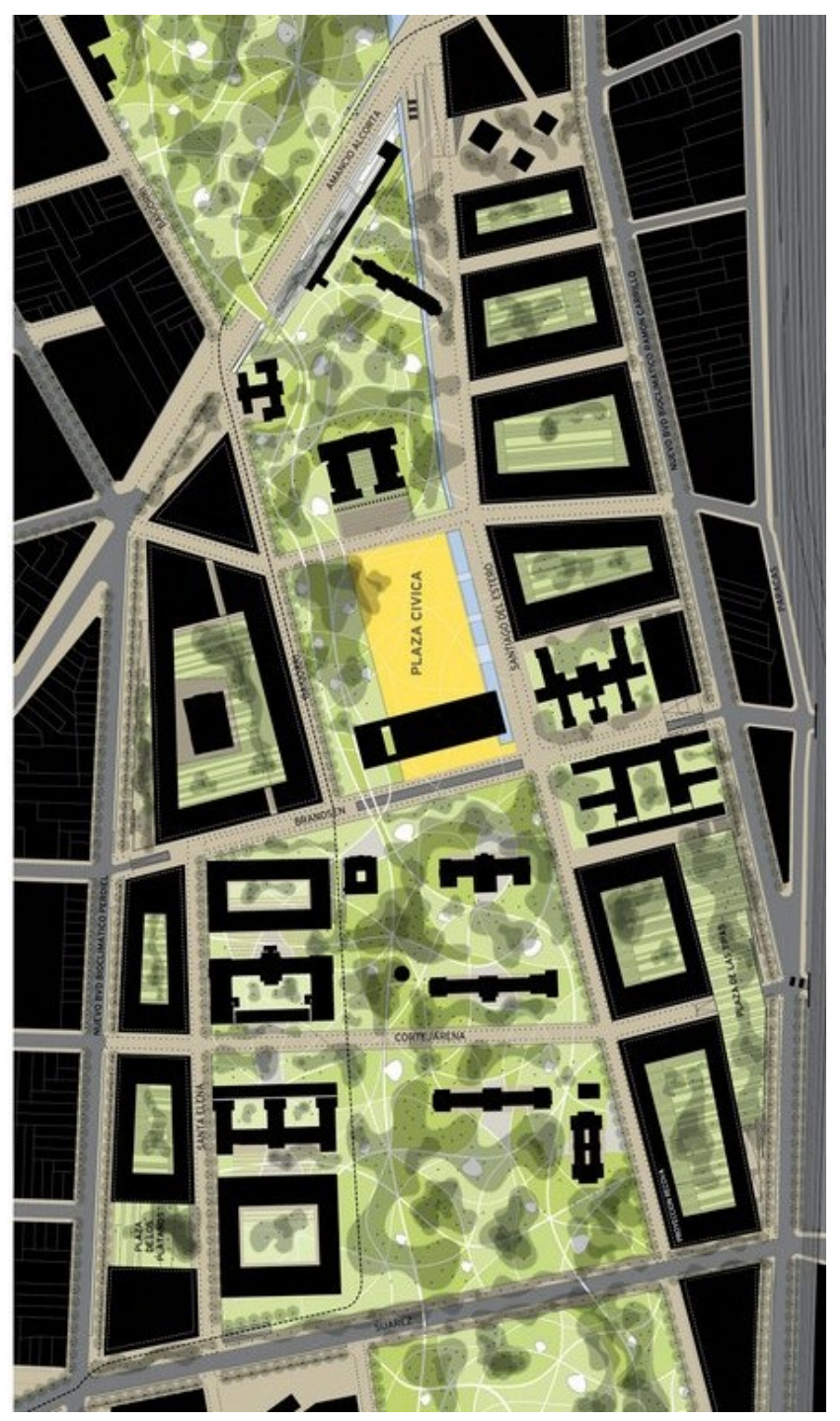

Fuente: Bases Concurso Nuevos Edificios del Distrito Gubernamental, SCA, 2011.

\begin{abstract}
${ }^{15}$ Talleres Protegidos de Rehabilitación en Salud Mental es un dispositivo alternativo que pertenece a la Dirección General de Salud Mental del Ministerio de Salud de la ciudad de Buenos Aires. Tiene como fin acompañar el proceso de resocialización de los pacientes mediante el aprendizaje de diversos oficios, tales como herrería, carpintería, industria textil, entre otros. Entre los distintos talleres que funcionan en este programa se encontraba el taller protegido 19, ubicado en terrenos del Hospital Borda, y destinado a aquellos pacientes que -por diversos motivos- no pueden salir del hospital.
\end{abstract}


Durante 2012 y 2013, los trabajadores del hospital y de Talleres Protegidos, junto con algunos legisladores opositores y algunas organizaciones sociales, desplegaron una serie de estrategias para obturar la construcción del distrito gubernamental. Entre ellas, se destacan la movilización, la difusión, la presentación de un proyecto alternativo, la articulación con el poder legislativo y la judicialización del conflicto. Como producto de esta última, los trabajadores obtuvieron a fines de 2012 una medida cautelar que impedía el comienzo de las obras.

En paralelo, el GCBA fue pasando de una estrategia de consenso hacia una más coercitiva que tuvo su epicentro el 26 de abril de 2013. Ese día la empresa constructora custodiada por oficiales de la Policía Metropolitana- ingresó al predio del Hospital Borda y demolió el taller protegido 19. Las fuerzas de seguridad reprimieron a trabajadores, legisladores, periodistas y pacientes. La gran difusión de este hecho -inédito en un hospital público-, la movilización de los trabajadores y la medida cautelar que suspende la obra impiden -por el momento- la construcción del centro cívico en ese predio. Luego de tres años conflictivos, el traslado de las sedes de gobierno al sur de la ciudad finalmente se concretó entre 2015 y 2016, pero adoptando otro nombre, otras características y otros emplazamientos (mapa 1).

De este modo, el procesamiento de esta política pública supuso la movilización de distintos actores con expectativas, intereses y proyectos contrapuestos en relación a ese espacio disputado. Esta manifestación de protesta u oposición a la implementación de una política pública -sostenida en la movilización de un repertorio variado de estrategias, recursos y argumentos por parte de los distintos actores- constituye una situación de conflicto (Melé, 2003). Particularmente un conflicto urbano, entendido como un "tipo particular de relaciones sociales que es el resultado de la convergencia espacio temporal de intereses incompatibles (razones de conflicto) entre dos o más actores (partes del conflicto) con respecto a los usos o localización de un pedazo concreto de territorio urbano (componente geográfico del conflicto)" (Von der Dunk et al, citado en Meneses Reyes, 2014: 295). En este sentido, se trata de un conjunto de relaciones que no pueden disociarse del territorio urbano concreto en el que tienen lugar.

En un conflicto, los actores construyen una "generalización" (montée en généralité) que les permite demostrar que su movimiento traspasa el interés particular Melé (2003a). Para ello, en su argumentación, se convocan valores y derechos que remiten a un interés colectivo, movilizando concepciones sobre el espacio urbano, la vida en la ciudad, la acción pública, etc. Esta generalización -al igual que la conceptualización de la cuestión (Oszlak y O’Donnell, 1981) y 
del propio conflicto- no se da de una vez y para siempre, sino que se construye a medida que se procesa la política y se disputa el conflicto, en un interjuego con los posicionamientos de otros actores. Así, advertimos que en el transcurso del conflicto todos los actores buscaron legitimar sus posicionamientos y acciones en un marco de intereses y derechos compartidos. Para el GCBA esto significó vincular la iniciativa del distrito gubernamental con un conjunto de intervenciones orientadas a "desarrollar el sur" (*anonimizado*). Por su parte, los trabajadores y organizaciones que se movilizaron en contra del distrito gubernamental desplegaron argumentos vinculados a la puesta en riesgo de un interés colectivo, de un bien común (la atención pública de la salud) frente a un proyecto que responde a un interés particular (un negocio inmobiliario) (*anonimizado*).

La conceptualización de la cuestión, de la política y del conflicto no es definitiva ni estable, sino que se disputa permanentemente a lo largo de su procesamiento, con cada una de las tomas de posición de los actores. En este sentido, en el siguiente apartado, veremos que cuando el conflicto es llevado al campo del derecho, continúa redefiniéndose a partir del repertorio de acciones y argumentos desplegado, en este caso, por los operadores jurídicos.

\section{DEL CONFLICTO AL LITIGIO JUDICIAL. LAS SUCESIVAS (RE)DEFINICIONES DEL CONFLICTO POR UN ESPACIO DISPUTADO}

El procesamiento de este conflicto como litigio se dio a través de tres demandas que conformaron luego expedientes distintos pero conectados entre sí, a partir de una herramienta procesal que es la conexidad de causas $^{16}$. Estas demandas son, por orden cronológico: a) Expediente №45.258 "Naddeo, María Elena y otros contra GCBA sobre amparo (art. 14 CCABA)", presentado en agosto de 2012; b) Expediente №45.995 "Frondizi, Marcelo Hernando y otros c/GCBA s/amparo (art. 14 CCABA)", presentado en octubre de 2012; y c) Expediente №G17-2013/1 “Frondizi, Marcelo Hernando y otros contra GCBA y otros sobre incidente de medida cautelar", de enero de 2013. En este apartado, describimos el recorrido de cada uno de estos expedientes (figura 1) y analizamos sus principales argumentos.

\footnotetext{
${ }^{16}$ Esta herramienta procesal permite que distintos expedientes se acumulen en un mismo juzgado y se tramiten como uno, decidiéndose en una sola sentencia.
} 
Figura 1: Recorrido de las causas judiciales

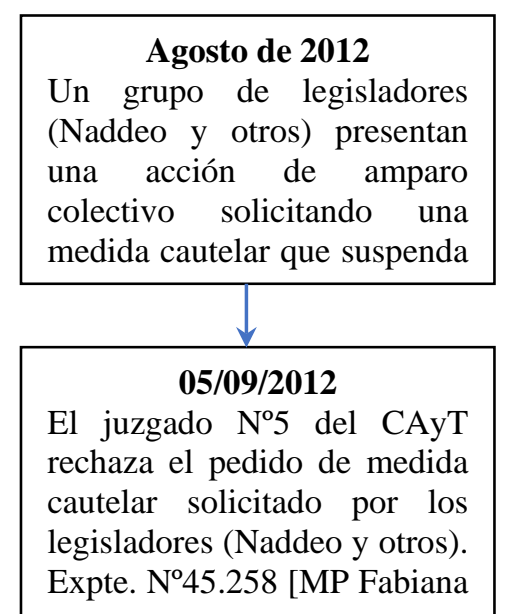

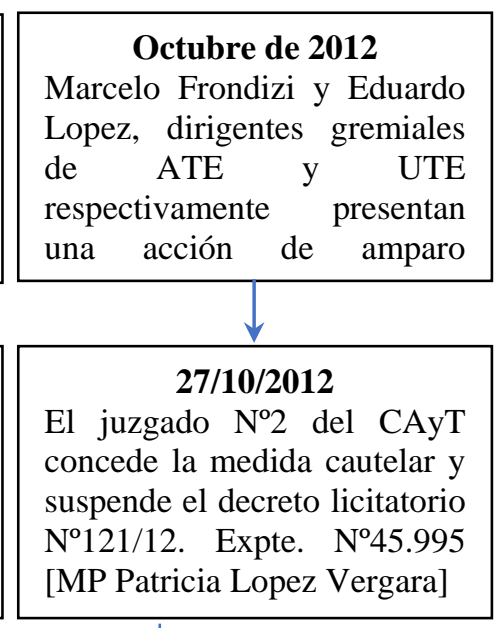

Octubre de 2012
Marcelo Frondizi y Eduardo
Lopez, dirigentes gremiales de ATE y UTE respectivamente presentan una acción de amparo El juzgado $\mathrm{N}^{\circ} 2$ del CAyT concede la medida cautelar y suspende el decreto licitatorio $\mathrm{N}^{\circ} 121 / 12$. Expte. $\mathrm{N}^{\circ} 45.995$ [MP Patricia Lopez Vergara]

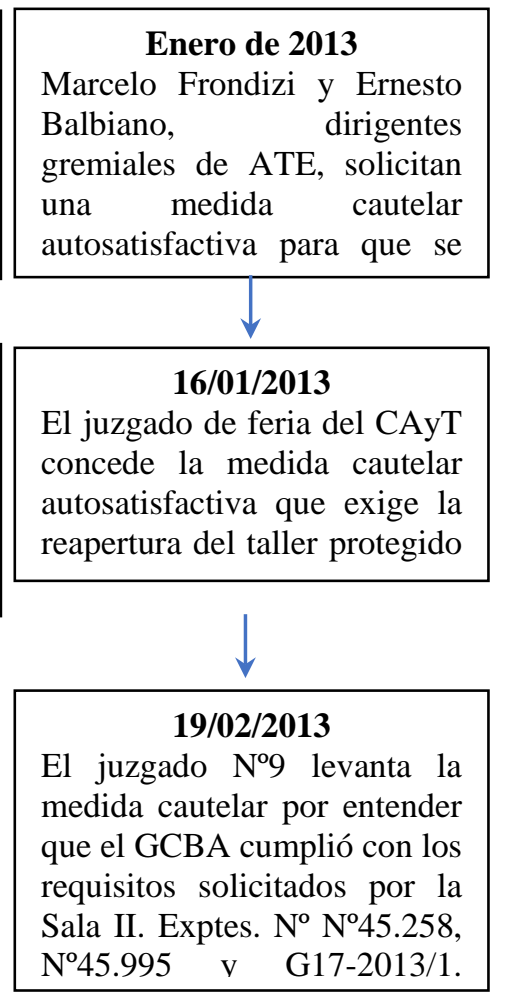

Apelación por parte de los demandantes.

\section{6/04/2013}

La Sala II de la Cámara de Apelaciones del CAyT confirma la medida cautelar se encontraba vigente y fija multas a los funcionarios del

\begin{tabular}{|l|l|}
\hline \multicolumn{3}{|c|}{$\mathbf{1 9 / 0 9 / 2 0 1 3}$} \\
\multicolumn{3}{|c|}{ La Sala II de la Cámara de } \\
Apelaciones del CAyT \\
reconfirma la medida cautelar \\
por incumplimiento de \\
requisitos. Exptes. $\quad \mathrm{N}^{\circ}$ \\
\hline
\end{tabular}

\section{6/12/2015}

El TSJ revoca el fallo de la Sala II, rechaza la reapertura del taller protegido $19 \mathrm{y}$ le saca las multas a los funcionarios del GCBA.

Fuente: elaboración propia. 
La demanda de los legisladores. Expediente No45.258 "Naddeo, María Elena y otros contra GCBA sobre amparo (art. 14 CCABA)

Esta primera demanda fue realizada por los entonces legisladores María Elena Naddeo, Virginia González Gass, Aníbal Ibarra y Fabio Basteiro, pertenecientes todos a diferentes partidos políticos de centro izquierda, opositores al gobierno del $\mathrm{PRO}^{17}$ en la ciudad. En agosto de 2012, este grupo de legisladores solicitó una medida cautelar que suspendiera la construcción de los edificios del distrito gubernamental dentro Hospital Borda "hasta tanto se cumplan las premisas establecidas en las respectivas leyes de Salud Mental de la Ciudad y Nacional en orden a la reubicación de pacientes y construcción de los centros necesarios para su tratamiento" ${ }^{18}$ y se diera intervención a la Legislatura.

En la demanda se despliegan tres argumentos. En primer lugar, se sostiene que el proyecto del distrito gubernamental debe ser aprobado por la Legislatura en la medida que implica afectar el uso principal y la zonificación del predio ${ }^{19}$. Los demandantes $-q u e$ se presentan "en calidad de diputados y miembros de la Comisión de Salud" - denuncian que no sólo no se dio intervención a la Legislatura, sino que falta información certera sobre el proyecto, lo que

viola elementales principios de publicidad que hacen a la esencia del régimen republicano y por añadidura afectan nuestras atribuciones como diputad@s de la ciudad, lo cual es decir que atentan contra la soberanía popular de la cual emana nuestro mandato. ${ }^{20}$

\footnotetext{
17 Propuesta Republicana (PRO) es el partido político conducido por el actual presidente de Argentina, Mauricio Macri. Este partido político gobierna la ciudad de Buenos Aires desde 2007, teniendo como jefe de gobierno durante los primeros dos períodos a Mauricio Macri (2007-2015), y actualmente a Horacio Rodriguez Larreta (2015 a la actualidad).

${ }^{18}$ Acción de amparo colectivo en la causa "Naddeo, María Elena y otros contra GCBA sobre amparo (art. 14 CCABA), expte №45.258, agosto de 2012.

${ }^{19}$ El predio donde se realizaría el distrito gubernamental tiene zonificación de distrito E4 "equipamiento especial", lo que significa que -tal como lo establece el Código de Planeamiento Urbano (CPU)- si se quiere alterar la situación del predio en una superficie mayor al 20\% del total de la parcela o incorporar nuevos usos, debe darse intervención a la Autoridad de Aplicación, "la cual evaluará la propuesta remitiéndola a la Legislatura para su tratamiento" (Acción de amparo colectivo, causa Naddeo, expte №45.258). Este aspecto técnico vinculado a los organismos que deben intervenir y el $20 \%$ del predio aquí aludido se vuelven objeto de discusión a lo largo de las distintas instancias por las que atraviesa el expediente.

20 Acción de amparo colectivo en la causa "Naddeo, María Elena y otros contra GCBA sobre amparo (art. 14 CCABA), expte №45.258, agosto de 2012, pp. 4. El subrayado es propio en todos las citas directas, excepto que se aclare lo contrario.
} 
A partir de esta secuencia se produce un implícito ${ }^{21}$ : si se afectan las atribuciones de los diputados, se viola la soberanía popular. Así, se invoca como garante, como fuente de legitimidad, la soberanía popular, el régimen republicano y, en última instancia, la democracia.

El segundo argumento remite al derecho a la salud de los pacientes. En este sentido, se relaciona el proyecto del distrito gubernamental con la reconversión del sistema de salud mental. En la demanda se afirma que hasta que no se creen los dispositivos de atención a la salud previstos en las leyes, no es posible llevar a cabo el proyecto. A la vez se sostiene que su desarrollo implica "la destrucción total", "un arrasamiento sin parangón en la historia reciente de la Ciudad":

se marcha a la destrucción total de un Hospital (...) con los enfermos sin ser reubicados en los lugares establecidos por las leyes que nunca fueron construidos. ${ }^{22}$

Va de suyo, que las obras afectan en forma directa a los pacientes ya que el movimiento de gente y máquinas, la polución y contaminación de todo tipo, los alteran grandemente con perjuicio inmediato sobre su salud. (...) No necesita mayor explicación señalar los daños que sufren (.... $)^{23}$

El uso de expresiones como "va de suyo" y "no necesita mayor explicación" producen el efecto de sentido de que es evidente que el avance del proyecto del centro cívico "afecta", "perjudica", "altera" la salud de los pacientes.

El tercer argumento, presentado como un "ítem más", de manera secundaria, se refiere a la obligación del GCBA de preservar e incrementar la cantidad de espacios verdes:

con el pretendido cambio de destino de una gran porción "verde" del Hospital Borda, el GCBA no sólo no está tomando las medidas adecuadas para aumentar los espacios públicos de uso común sino que está incumpliendo con su obligación mínima de preservarlos. ${ }^{24}$

De esta forma, ya en esta primera demanda, el conflicto por los usos de un espacio urbano es redefinido cuando ingresa al campo jurídico, en principio transformando los argumentos de los actores en derechos afectados o lesionados: el derecho cívico (o la soberanía popular); el derecho a la salud y el derecho a un ambiente sano.

El 5 de septiembre de 2012 la jueza Schafrik del juzgado №5 de primera instancia del CAyT rechazó este pedido de medida cautelar. En el fallo se despliegan dos argumentos

\footnotetext{
${ }^{21}$ Aquellos contenidos que se extraen de un enunciado y que no constituyen, en principio el objeto verdadero de la enunciación (Maingueneau, 1996).

${ }^{22}$ Acción de amparo colectivo en la causa "Naddeo, María Elena y otros contra GCBA sobre amparo (art. 14 CCABA), expte №45.258, agosto de 2012, pp. 5.

${ }^{23}$ Acción de amparo colectivo en la causa "Naddeo, María Elena y otros contra GCBA sobre amparo (art. 14 CCABA), expte №45.258, agosto de 2012, pp. 6.

${ }^{24}$ Acción de amparo colectivo en la causa "Naddeo, María Elena y otros contra GCBA sobre amparo (art. 14 CCABA), expte №45.258, agosto de 2012, pp. 6.
} 
principales para rechazar el pedido: a) que la Legislatura había intervenido al aprobar el presupuesto general del GCBA para el ejercicio 2012, en el que el centro cívico tenía asignada una partida presupuestaria; y b) que "las actividades del taller protegido ubicado en el polígono del terreno destinado al distrito cívico habían sido trasladadas a un espacio en condiciones de habitabilidad y funcionalidad óptimas, sin que pudiera verificarse interferencia con ningún servicio perteneciente al Hospital de Salud Mental José Tiburcio Borda" ${ }^{25}$. Posteriormente, los legisladores apelaron esta sentencia negativa, ampliando sus argumentos, entre los que sumaron dos nuevas cuestiones. Por un lado, que el predio donde funciona el Hospital Borda había sido donado por la familia Zeballos al antiguo Hospicio de las Mercedes para ser destinado a la atención de la salud; y por el otro, que uno de los pabellones del hospital fue declarado monumento histórico. Ambas cuestiones constituirían "impedimentos para la modificación del destino y la destrucción del predio" ${ }^{26}$.

\section{La demanda de los trabajadores - suspensión del decreto №121/12 27 . Expediente №45.995 “Frondizi, Marcelo Hernando y otros C/GCBA s/amparo (art. 14 CCABA)"}

En octubre de 2012, el Secretario General de la Junta Interna de Delegados de Talleres Protegidos del sindicato Asociación de Trabajadores del Estado (ATE), Marcelo Frondizi, y el Secretario General de la Unión de Trabajadores de la Educación (UTE), Eduardo Lopez, presentaron una acción de amparo contra el GCBA para suspender la ejecución del distrito gubernamental. Para ello solicitaron el patrocinio del Ministerio Público de la Defensa -que por entonces tenía una Unidad Especial Temática (UET) sobre Patrimonio Histórico ${ }^{28}$ a cargo del Dr. Roberto Gallardo. La acción de amparo fue presentada en el juzgado de turno №2 del fuero CAyT y en ella se solicitaba la suspensión de la obra del centro cívico con el argumento de que en el predio existían inmuebles catalogados con protección patrimonial. En este sentido, se pedía protección edilicia y ambiental para el área.

no sólo en razón del valor paisajístico, simbólico y social del mismo sino por encontrarse bajo el mismo un importante yacimiento arqueológico

\footnotetext{
${ }^{25}$ Cámara de Apelaciones en lo CAyT, Sala II, expte. №45.995, resolución del 28/12/2012, pp. 13.

${ }^{26}$ Cámara de Apelaciones en lo CAyT, Sala II, expte. №45.995, resolución del 28/12/2012, pp. 13.

27 Se trata del decreto de licitación de la obra para la construcción del distrito gubernamental.

${ }^{28}$ Esta unidad fue creada mediante la resolución №299/12 de la Defensoría General el 14/09/2012; luego se modificó su estructura el 22/03/2013 con la resolución №99/13 y finalmente el 8/10/2014 fue disuelta de hecho mediante la resolución №576/14.
} 
urbano, constituido por túneles, sótanos y pasadizos que no han sido aun debidamente relevados ${ }^{29}$.

Según esta demanda, la existencia de inmuebles con protección patrimonial justifica la intervención de otros organismos vinculados a la temática patrimonial, como la Comisión Nacional de Museos y de Monumentos y Lugares Históricos y el Instituto Nacional de Antropología y Pensamiento Latinoamericano, ambos bajo la órbita del Estado Nacional.

Así el conflicto por el espacio urbano disputado es traducido por los operadores jurídicos como un problema de protección patrimonial. La defensora de Cámara que elaboró la demanda ${ }^{30}$ y patrocinó a los delegados gremiales, la Dra. Mariana Pucciarello, nos comentaba que tomó la decisión de utilizar los problemas técnicos que tenía el decreto licitatorio №121/12 como estrategia argumentativa ya que dichos elementos habilitan más fácilmente el dictado de una medida cautelar:

Yo vi que había varios problemas, pero fundamentalmente había un problema grave en la licitación, lo cual es un problema típico de derecho administrativo. Y estos problemas, como son técnicos, despejan por completo cualquier duda. Puede haber algún interés político o gremial en el tema, en la defensa, pero cuando se detecta un tema técnico importante es como que ese tema deja en segundo plano las consideraciones no jurídicas y hace que sea más fácil (Entrevista a Defensora de Cámara, junio de 2016).

Así, el sentido práctico (Bourdieu, 1980) de la operadora jurídica -que manifiesta conocer las reglas del campo- resulta clave para terminar de redefinir el conflicto en el campo del derecho de una forma más efectiva para obtener un fallo favorable. De esta manera, en lugar de sostenerse argumentos vinculados al uso de ese espacio urbano para la atención de la salud mental -como en el expediente №45.258-, se privilegian cuestiones técnicas vinculadas a la protección patrimonial de un predio catalogado. El 27 octubre de 2012 los trabajadores del hospital obtuvieron una medida cautelar -dictada por la jueza de primera instancia Patricia Lopez Vergara- que suspendió el decreto licitatorio №121/12. Medida que dos meses más tarde fue confirmada por la Sala II de la Cámara de Apelaciones del mismo fuero. En esta última sentencia, los jueces de cámara también revocaron el primer fallo de la causa "Naddeo" (expte №42.258) y unificaron ambos expedientes que se radicaron a partir de allí en el juzgado de primera instancia №9 del fuero CAyT.

\footnotetext{
${ }^{29}$ Juzgado de primera instancia en lo CAyT №2, expte. №45.995, resolución del 27/10/2012, [MP Patricia Lopez de Vergara], pp. 1.

30 Por ser, además, defensora de la Unidad Especial Temática sobre Patrimonio Histórico.
} 
Segunda demanda de los trabajadores - Reapertura del taller protegido 19. Expediente №G17-2013/1 “Frondizi, Marcelo Hernando y otros contra GCBA y otros sobre incidente de medida cautelar"

Por último, la tercera demanda en relación a este conflicto fue presentada en enero de 2013 nuevamente por Marcelo Frondizi y Ernesto Balbiano -Delegado General Adjunto ATEcon el patrocinio del Defensor General Adjunto Roberto Gallardo. En esta oportunidad, los trabajadores solicitaron una medida cautelar autosatisfactiva ${ }^{31}$ contra el GCBA para que se ordenara la reapertura del taller protegido 19, que había sido dejado fuera de funcionamiento por orden del Ministerio de Salud de la ciudad, bajo el argumento de que las instalaciones estaban en malas condiciones.

En la demanda se sostiene que "las autoridades del Hospital decidieron, de hecho, el cierre del Taller que se trata, sin notificar a los trabajadores y profesionales" 32 y que esta decisión afecta "los derechos de los internos que asisten al mismo". Para legitimar este argumento se remite como garante a otro discurso constituyente, el discurso científico, citando la voz de "especialistas de renombre dentro de la comunidad médica" quienes mediante una nota enfatizan la importancia de la reapertura del taller.

Esta medida autosatisfactiva fue concedida por la jueza Elena Liberatori durante la feria judicial. Luego, en febrero del mismo año, la jueza Danas -del juzgado №9 donde tramitaban los otros dos expedientes- dictó la conexidad de las causas y declaró este proceso "abstracto" por considerar que el taller 19 estaba en funcionamiento en otras instalaciones. Los demandantes apelaron esta decisión y a partir de aquí los tres expedientes se tramitaron de manera conjunta. En el último apartado, nos referimos a la continuidad de estos procesos, por el momento, nos interesa señalar algunas cuestiones en relación a las distintas definiciones del conflicto cuando es judicializado.

\footnotetext{
31 "A diferencia de la medida cautelar tradicional, el fin de la medida autosatisfactiva no es asegurar los efectos prácticos de otro proceso, sino satisfacer en forma definitiva la pretensión. Esto significa que con su dictado se agota el interés de la parte en el proceso" (Juzgado de feria de primera instancia en lo CAyT, expte. G17-2013/1, resolución del 16/01/2013 [MP Elena Liberatori], pp. 4).

32 Juzgado de feria de primera instancia en lo CAyT, expte. G17-2013/1, resolución del 16/01/2013 [MP Elena Liberatori], pp. 4
} 


\section{Del derecho a la salud a la conservación del patrimônio}

Las tres demandas, reseñadas previamente, dan cuenta de los diversos modos en que fue reelaborado el conflicto al ingresar en el campo del derecho. Esta operación de traducción del conflicto en términos de derechos afectados -es decir, la actualización local del derecho (Azuela y Mussetta, 2009)- es una de las aristas de la productividad social de este conflicto. Si bien la primera demanda presentada por los legisladores (expte №42.258) tomó como argumento principal la afección del derecho a la salud de los pacientes del hospital, es en realidad la segunda causa (expte №45.995) -en la que se plantearon las cuestiones patrimoniales- la que finalmente dio lugar a la medida cautelar. De esta manera, se produjo una separación entre el procesamiento de la política pública, donde aún hoy se sigue sosteniendo una disputa por el uso de un espacio vinculado a la atención de la salud mental, y el procesamiento del litigio judicial, en el que se puso en juego principalmente la conservación del patrimonio urbano.

En el fallo que concedió la medida cautelar (expte №45.995) se observa que el sustento normativo en el que se basó la decisión de la jueza estuvo estrictamente vinculado a la preservación del patrimonio histórico y cultural. Esto posibilitó que la jueza dictara la suspensión del decreto licitatorio №121/12 por no haberse cumplido con los requisitos necesarios para la realización de una obra en un predio con estas características. Particularmente la intervención de la Secretaría de Cultura y del Consejo del Plan Urbano Ambiental; y la realización de un estudio de impacto ambiental.

Luego, en la sentencia confirmatoria de la Sala II se retomaron los argumentos de carácter patrimonial para contestar la apelación del GCBA, quedando planteado el conflicto en los siguientes términos:

La tensión, en concreto, resulta de la ejecución de una obra que, hasta el momento, carece de evaluación de impacto ambiental y cuya puesta en marcha podría implicar, al menos, un riesgo para los bienes tutelados legal y constitucionalmente. ${ }^{33}$

En esta redefinición del conflicto jugó un rol central el modo en que fue tematizado el espacio en cuestión, que fue movilizado como recurso (Melé, 2003) para justificar determinadas acciones, en este caso su protección. Así, por ejemplo, su caracterización como patrimonio "histórico, cultural y social" habilitó, por un lado, tramitar la demanda en días y horarios inhábiles por su carácter de urgente. Por el otro, permitió que los jueces admitieran una

\footnotetext{
${ }^{33}$ Cámara de Apelaciones en lo CAyT, Sala II, expte. №45.995, resolución del 28/12/2012, pp. 21.
} 
legitimidad amplia para la representación de los actores al ponerse en juego un bien colectivo. En la sentencia que dicta la primera medida cautelar se justifica la urgencia, la "inmediata intervención judicial a fin de evitar un perjuicio irreparable" que sería la afección del patrimonio cultural de la ciudad. Asimismo, se construye una generalización (monteé en généralité) (Melé, 2003) al plantear que el patrimonio histórico y cultural es "de importancia vital para la comunidad toda", y que la "protección del interés público ambiental e histórico cultural (está) por encima de toda consideración económica y administrativa" ${ }^{34}$.

Una vez que el conflicto quedó definido como un problema de conservación patrimonial, todos los argumentos de las partes y de los jueces en sus distintas resoluciones se orientaron a definir si se cumplieron o no a los requisitos exigidos en el primer fallo y confirmados en segunda instancia. En este sentido, por ejemplo, se discutió en torno a la correcta realización de la evaluación de impacto ambiental. En varias oportunidades el GCBA afirmó haber realizado el correspondiente estudio, mientras que los trabajadores y legisladores cuestionaron el modo en que fue realizado. Otro aspecto que ocupó varias páginas en los fallos es la discusión en torno a la intervención de la Legislatura. El repertorio de argumentos en torno a estas discusiones implicó, en muchas sentencias, la apelación a normativa urbana y a la voz de los "especialistas" en urbanismo como fuente legitimante, dándose una articulación entre dos discursos constituyentes: el judicial y el científico.

De esta forma, los argumentos vertidos tanto por las partes como por los jueces a lo largo del litigio pusieron de manifiesto que los motivos que movilizan quienes se oponen a la construcción del centro cívico en el procesamiento de la política pública -relacionados con la atención de la salud mental y con el uso de ese espacio urbano- quedaron relegados en un segundo plano. En su lugar, cobraró relevancia una serie de aspectos técnicos relacionados con la conservación del patrimonio. Esto es así debido a que, en el campo del derecho, muchas veces las estrategias procesuales tienen un mayor peso que los argumentos $y$, en este sentido, los operadores jurídicos realizan una "traducción", privilegiando aquellos argumentos que sirven de base para una estrategia jurídica más efectiva (Melé, 2016).

\footnotetext{
${ }^{34}$ Juzgado de primera instancia en lo CAyT №2, expte. №45.995, resolución del 27/10/2012, [MP Patricia Lopez de Vergara].
} 


\section{EL ROL DE LOS OPERADORES JURÍDICOS DURANTE EL LITIGIO}

Hasta aquí vimos cómo un conflicto en torno a los usos de un espacio urbano fue redefinido al ingresar al campo del derecho. Si bien se tramitaron tres expedientes unificados con diferentes argumentos cada uno de ellos, el que terminó primando para la obtención de la medida cautelar fue aquel en el que se puso en juego más fuertemente la conservación del patrimonio. En este caso, fueron los operadores jurídicos quienes transformaron la definición, construyendo la demanda como un derecho colectivo lesionado -el patrimonio histórico y cultural- y procesaron así el conflicto en términos de litigio judicial.

En este bloque analizamos cómo los operadores jurídicos han contribuido en esta redefinición y, por tanto, en el desarrollo del conflicto. Asimismo prestamos especial atención a las prácticas judiciales de los operadores para demorar y acelerar las distintas etapas del litigio. Para su mejor comprensión, inscribimos estas prácticas en un entramado de relaciones de poder y de agendas propias de los operadores, para lo cual es preciso explorar brevemente la estructura del fuero CAyT de la ciudad de Buenos Aires.

\section{Las condiciones históricas y políticas del activismo judicial en CABA}

Con la reforma constitucional de 1994, se define la autonomía de la Ciudad de Buenos Aires lo que conlleva -a partir de la sanción de la Constitución local en 1996- la creación de una nueva institucionalidad para este distrito. En lo que respecta al poder judicial, el proceso de autonomización supuso algunos problemas en tanto que en la ciudad de Buenos Aires ya operaba la estructura del poder judicial nacional. Esto significa que, en lugar de crearse de cero, el Poder Judicial de la Ciudad Autónoma de Buenos Aires (CABA) debía conformarse a partir del traspaso de los fueros federales al ámbito local ${ }^{35}$. Este traspaso

no está hecho y es altamente conflictivo, por un montón de elementos que van desde lo salarial, hasta el estatus, hasta ciertas cuestiones de organización y adaptación (...) (Integrante del Ministerio Público de la Defensa (MPD) de la Ciudad de Buenos Aires, junio de 2016).

\footnotetext{
${ }^{35}$ Con excepción de las materias que son federales y que se conservan en el ámbito del Poder Judicial de la Nación, tales como el comercio de "estupefacientes, el contrabando, la evasión fiscal, el lavado de dinero y otros delitos que afectan la renta y la seguridad de la nación" (Sitio web del Ministerio de Justicia y Derechos Humanos de la Nación, http://www.jus.gob.ar/la-justicia-argentina/administracion-dejusticia.aspx. Captura: 21/10/2016.
} 
Sin embargo, hay dos ámbitos que no tenían equivalente en el Poder Judicial Nacional y que, por tanto, en lugar de traspasarse, se crearon de cero en la ciudad de Buenos Aires. Estos son el fuero Contravencional, que comenzó a trabajar con funcionarios designados en comisión de lo que era el Tribunal de Faltas, y el fuero Contencioso Administrativo y Tributario que fue conformado a través de cargos concursados y que es en el que se procesan todas las causas donde el GCBA "es parte", ya sea como actora o como demandada. En la actualidad el Poder Judicial de la CABA está integrado por los tribunales de primera y segunda instancia de estos dos fueros, el TSJ, el Consejo de la Magistratura, y el Ministerio Público, que incluye a la Defensoría, la Fiscalía y la Asesoría Tutelar.

En funcionamiento desde el año 2000, el CAyT tuvo desde sus orígenes, según destaca una operadora judicial,

un tratamiento de los derechos sociales, te diría, con un sesgo bastante progresista por la composición del fuero. (...) Salieron 12 jueces de distinta composición, algunos de la profesión, otros del Poder Judicial, otros de organismos del Estado, todos con una calificación alta y con una mirada que generó una perspectiva bastante favorable a la concreción de derechos sociales. Y eso hizo que salieran muchos fallos comentados, y uno de los temas estrella acá es el derecho a la vivienda ${ }^{36}$ (Integrante del MPD de la CABA, junio de 2016).

Este carácter progresista de algunos de los jueces del fuero se da en el marco de un debate doctrinario dentro del campo jurídico acerca de la relación entre los poderes del Estado y el rol del Poder Judicial en el control de las políticas públicas para el efectivo cumplimiento de los derechos fundamentales (Gargarella y Maurino, 2011; Sabsay, 2012). En palabras de un juez de la CABA:

En los tribunales hay dos corrientes. Hay una corriente que considera que las políticas públicas son, como su nombre lo indica, cuestiones políticas, y que por lo tanto están ajenas al control judicial. (...) Esta es una corriente tradicional-clásica, por no decir antigua. Y hay otra corriente, con distintos grados no uniformes de profundización, que entiende lo contrario, entiende que las políticas públicas están sujetas a control judicial de constitucionalidad, tanto sea en su acción como en su omisión. O sea, controlable es el contenido de las políticas públicas o controlable es la inexistencia de las políticas públicas. (Juez de primera instancia del fuero CAyT, abril de 2011)

\footnotetext{
${ }^{36}$ Algunos de los casos más resonantes del fuero son: "Alba Quintana, Pablo c/ GCBA y otros s/ amparo"; "Asociación Civil por la Igualdad y la Justicia contra GCBA sobre amparo" (por riesgo sanitario en la Villa 31); "Di Filippo, Facundo Martín c/GCBA s/ amparo" (por elecciones en la Villa 31); "Zarate Villalba Juan Ramón y otros contra GCBA sobre amparo (art. 14 CCABA)" (por la urbanización de la Villa Rodrigo Bueno).
} 
Las características del CAyT, sumadas al giro político de las organizaciones sociales de litigio $^{37}$, dieron lugar a un nuevo activismo judicial en materia de derechos económicos, sociales y culturales (DESC) (Abramovich, Pautassi, 2009; Delamata, 2016) sobre todo durante el primer mandato del PRO (2007-2011). Este proceso que se vio mermado a partir de la modificación de la composición del fuero entre los años 2009 y 2013. Los concursos ordenados por las leyes 3.318/09 y 2.152/13, modificatorias de la Ley Orgánica del Poder Judicial, duplicaron los juzgados de primera instancia alcanzando en la actualidad un total de 24 y se creó una tercer Sala de la Cámara de Apelaciones, "primando el nombramiento de jueces de perfil conservador" (Delamata, 2016: 582).

Relacionar las prácticas de los operadores jurídicos a lo largo de este litigio con los orígenes, estructuración y conformación del Poder Judicial porteño nos invita a incorporar la concepción del Estado como actor heterogéneo también para el análisis del poder judicial y su incidencia en las políticas públicas. La noción de burocracia estatal -“como actor social agregado y complejo expuesto a demandas e intereses a menudo incompatibles, pero dotados de recursos, grados de autonomía y capacidad de articulación hacia las profundidades de la sociedad civil y las alturas del Estado" (Oszlak, 1977: 19)- fue desarrollada para pensar, sobre todo, el poder ejecutivo. Sin embargo, resulta interesante ampliar esta perspectiva analítica a los tres poderes del Estado, y especialmente, al judicial en tanto que -como se observa a lo largo de este artículo - cada uno de ellos y entre sí son producto de cristalizaciones de diversos conflictos en su interior.

\section{El carácter indeterminado del derecho y las estrategias de los operadores jurídicos}

El caso que aquí estudiamos fue procesado como litigio a partir del año 2012, cuando la composición del fuero ya había sido modificada. Al observar en detalle cómo actuaron los operadores jurídicos al momento de presentar las demandas es posible identificar una apuesta por buscar radicar las mismas en los juzgados reconocidos como de "corte progresista". Así, por ejemplo, la denuncia de Marcelo Frondizi (expte №45.995), patrocinada por abogados del

\footnotetext{
${ }^{37}$ A partir de la reforma constitucional de 1994 y la sanción de la Constitución local en 1996, se asignan competencias a las organizaciones no gubernamentales (ONG) para interponer acciones de amparo en representación de derecho de incidencia colectiva. Esto abre la puerta a la intervención de estas organizaciones en los litigios. Para mayor información sobre este proceso, ver Bercovich et al (2013); Delamata (2016)
} 
Ministerio Público de la Defensa, fue presentada en horario judicial inhábil. Esto posibilitó que fuera tomada por el juzgado de turno №2, cuya jueza subrogante era la Dra. Lopez Vergara, integrante del CAyT desde el año 2000. Luego, la segunda demanda de Frondizi (expte №G172013/1), fue presentada en enero de 2013, durante la feria judicial. Esto permitió que el juzgado de turno №4 de la Dra. Elena Liberatori, integrante del fuero desde los 2000, tramitara la denuncia y dictara la medida cautelar autosatisfactoria. Así, presentar las demandas en horarios y días inhábiles constituye una estrategia de los operadores jurídicos para tener un margen de elección de los jueces que intervendrán -al menos en un primer momento- en el litigio, en un contexto en el que la estructura de oportunidades en relación al activismo judicial había comenzado a cerrarse.

Al entrar en el mundo del derecho aparecen relaciones de poder que son propias del campo jurídico y que pueden afectar el resultado del conflicto (Azuela, 2014). En este caso, la posibilidad de elegir en qué juzgado se radica inicialmente la causa fue lo que permitió que se concediera o no una medida cautelar a favor de los actores movilizados, lo que habilitó -al menos en este primer momento-ganar tiempo.

Otro aspecto -propio de la estructura que adopta el fuero- y que incidió fuertemente en el procesamiento de este litigio es el modo en que está organizado el Ministerio Público de la Defensa. Mientras que la designación de defensores es por instancias, replicando la estructura de los tribunales; la Procuración General -que es el organismo que representa al GCBA en los litigios- está organizada como un cuerpo de abogados y es el procurador quien asigna las causas. Esta diferencia en la organización de ambos organismos hace que a medida que el expediente (o sus diferentes incidentes) van cambiando de instancia, se modifique el defensor, mientras que el abogado del GCBA sigue siendo el mismo. Además de significar una duplicación de tareas (Pucciarello, 2011), esta organización trae dificultades en el armado y cambios en el enfoque de la defensa. Así, por ejemplo, en uno de los expedientes iniciados por Frondizi, se cambió de defensor al menos cinco veces.

Esta cuestión también fue planteada como un incidente en el litigio (expte №45.995/3) en tanto que los defensores pidieron la recusación de la jueza Andrea Danas

por entender que la magistrada designó a la Dra. Lorena Castro Feijoó como defensora actuante (...) sin correrles un traslado previo a fin de ejercer su derecho de defensa, lo que, consideran, constituye un verdadero prejuzgamiento. (...) Sostienen que la cuestión genera un 
caprichoso tironeo de defensas que produce una situación infeliz respecto de sus patrocinados. ${ }^{38}$

Este pedido de recusación de la jueza fue rechazado por la Sala II por entender que "la mera discrepancia de los incidentistas con el criterio de la juez no comprueba la existencia de alguna circunstancia que, razonablemente, permita otorgar fuerza de convicción a esa afirmación" ${ }^{39}$. La apelación a este tipo de recursos por parte de los operadores jurídicos -más allá de que constituyen estrategias para obtener ciertos resultados a su favor- pone de manifiesto la existencia de tensiones dentro del poder judicial porteño. Asimismo, permite observar que los operadores tienen sus propias agendas, relacionadas con el capital propio que se disputa en el campo jurídico, y se articulan de manera impredecible con los intereses de los actores principales en el conflicto (Azuela, 2014).

Particularmente, la conservación del patrimonio urbano constituye un tema de agenda actualmente en la ciudad de Buenos Aires, al igual que en otras ciudades del mundo (Gonzalez Bracco, 2013). Esto también permea el poder judicial e impacta en su organización institucional, por ejemplo, al crearse a fines de 2012 -a pedido de un grupo de legisladores y de organizaciones vecinales en defensa del patrimonio histórico- una UET sobre Patrimonio Histórico Urbano, dentro de la Defensoría General, que tiene por objetivo asesorar y actuar judicialmente en relación con esta temática ${ }^{40}$. La existencia de esta UET, a cargo del entonces Defensor Adjunto Interino Roberto Gallardo, posibilitó que los actores movilizados tuvieran un margen de maniobra en la elección de los defensores públicos que los patrocinarían en la causa. En lugar de recurrir a la defensoría de primera instancia de turno, tuvieron el patrocinio de defensores con una mirada progresista sobre IOS DESC, quienes como operadores jurídicos integrantes de una UET de patrimonio, formularon la demanda en estos términos. Que la denuncia fuera encausada a través de esta unidad también influyó en la redefinición del conflicto.

En el procesamiento de una política pública, cuando alguno de los actores no tiene la capacidad de incidir en ella de manera directa, lo hace en forma indirecta, obstaculizando, bloqueando o demorando las posibilidades de otros actores (Rodriguez y Di Virgilio, 2011). Para ello, la judicialización del conflicto constituye una estrategia clave, en tanto que

(...) el efecto más generalizado en el recurso al derecho es precisamente el de extender los tiempos de la decisión. Independientemente de la capacidad de determinar una decisión final por los procesos jurídicos, si

\footnotetext{
${ }^{38}$ Cámara de Apelaciones en lo CAyT, Sala II, expte. №45.995, resolución del 28/12/2012.

${ }^{39}$ Cámara de Apelaciones en lo CAyT, Sala II, expte. №45.995, resolución del 28/12/2012.

${ }^{40}$ Resolución №299/12 de la Defensoría General.
} 
los actores de un conflicto pueden influir en algo recurriendo al derecho es ni más ni menos que en la temporalidad de la situación. Ganar tiempo se vuelve frecuentemente ganar todo, mismo si es sólo por un tiempo (Azuela y Melé, 2005: 7, traducción propia).

Esta estrategia de ganar tiempo ha resultado productiva considerando que el proyecto del distrito gubernamental se conoció en 2012, los actores movilizados lo judicializaron hacia fines de ese año; y al momento de escritura de este artículo (mayo de 2018) no hay una sentencia definitiva en dos de las tres causas en relación a este tema. ¿Cómo resulta esto posible? Tal como plantean Azuela y Melé (2005: 6), esto se debe, en parte, a las propias indeterminaciones del derecho, a su carácter dinámico y a su textura abierta. Al contrario de lo que suele creerse, los cambios en la legislación y las posibilidades de interpretación de los jueces -la doctrina judicial- "implican una indeterminación tanto en la aplicación de la regla como en su definición". Esto otorga un margen de maniobra a los jueces en la interpretación de las leyes que habilita decisiones contrapuestas, según cuáles sean los argumentos y normas que se privilegien. Esto torna muy difícil la anticipación de los efectos jurídicos; a la vez que dota a los operadores de una gran cantidad de herramientas para aprovechar este carácter indeterminado del derecho.

Entonces, así como los actores extrajurídicos acuden al campo del derecho para demorar, en este caso, la implementación de una política urbana; los operadores jurídicos -de ambas partes- hacen uso de diversas herramientas procesales para ganar tiempo en el procesamiento del litigio. En el caso que aquí analizamos, algunas de estas herramientas fueron la producción de incidentes en relación a la acumulación de causas (mientras que el GCBA pedía la conexidad de cuatro expedientes para que sean radicados en un juzgado que podía fallar a su favor, los actores buscaron impedir sin éxito esta acumulación); a la representación de los actores; a la falta de legitimidad de los demandantes; y una variedad de recursos (de apelación, de inconstitucionalidad, de reposición in extremis, de queja por recurso de inconstitucionalidad denegado, pedido de recusación de una jueza, entre otros ${ }^{41}$ que complejizaron y demoraron el proceso judicial. En términos de una operadora jurídica, un incidente

es un planteo específico que es materia de apelación, entonces como es materia de apelación, no suspende todo el expediente, sube sólo el incidente (...) Esto significa que puede haber un montón de apelaciones antes de la sentencia. Y esto complica mucho la tramitación del expediente, pero a veces lo complica porque el tema es complicado, y

\footnotetext{
${ }^{41}$ No es nuestro objetivo profundizar en cada uno de estos recursos y en sus efectos específicos en el tratamiento de cada expediente, sino más bien reseñarlos y enumerarlos para ilustrar cómo su uso -de forma más general- contribuye a la demora en el procesamiento del litigio.
} 
otras complicaciones pueden derivar de cómo se lleva el expediente (Integrante del MPD de la CABA, junio de 2016).

Para el caso que aquí analizamos, este tipo de herramientas tornaron aún más compleja la causa debido a la gran cantidad de operadores jurídicos que intervinieron en su procesamiento. Además de los juzgados y cámaras, se involucraron las tres partes del Ministerio Público: la Defensoría (patrocinando a los actores), la Asesoría Tutelar (por afectar a los pacientes del hospital) y la Fiscalía (por estar involucrado un "interés general"). Esto hace que, ante cada incidente, todos (o la mayoría) de los operadores se expidan, lo que produce mayores demoras.

\section{LOS EFECTOS SOCIALES DE LA JUDICIALIZACIÓN}

Siguiendo a Cosacov (2014: 149) “la judicialización es sólo una de las arenas por las que atraviesa una controversia", en este caso, en torno al desarrollo de una política pública. De esta forma, la judicialización reconfigura el conflicto pero no lo agota. Así, mientras que se procesaba el litigio en el campo del derecho, los actores recurrieron a otras estrategias y movilizaron otros recursos. Los trabajadores del hospital y de talleres protegidos que se oponen a la construcción del centro cívico, apoyados por organizaciones sociales, se movilizaron y realizaron un acampe dentro del taller protegido 19 durante el segundo semestre de 2012. En consonancia con esta estrategia de movilización, buscaron difundir la problemática con el objetivo de que tomara carácter público. Esto se complementó con la estrategia judicial, en tanto que las sentencias judiciales favorables legitimaban la postura de estos actores, a la vez que contribuían a difundir el conflicto. A medida que surgía una novedad en cada una es estas instancias judiciales, el Hospital Borda volvía a ser noticia ${ }^{42}$, y el nivel de conocimiento público del problema se iba incrementando.

Por su parte, el GCBA, mientras disputaba en el terreno judicial -apelando los distintos fallos, interponiendo recursos procesales para favorecer su postura en el marco del litigio y reuniendo pruebas para conseguir una resolución que lo favoreciera- intentaba paralelamente construir consensos con los distintos gremios y autoridades del hospital ofreciendo a cambio realizar las refacciones pendientes, entre ellas la conexión de gas de una parte de edificio.

\footnotetext{
42 El día 10 de agosto de 2012 Página 12 titulaba "El conflicto del Borda va a la justicia", Diario Popular señalaba el 29 de octubre de 2012 "La Justicia frenó la construcción de un centro cívico en el Borda", mientras que la CTA lanzó con comunicado el mismo día titulando "Borda: un triunfo de los trabajadores".
} 
También disputaba en el campo de la opinión pública, buscando legitimar el proyecto del distrito gubernamental, presentándolo como una solución para "desarrollar la zona sur" y resolver así el desequilibrio entre una "zona norte pujante" y un "sur deteriorado".

Al observar la articulación entre conflicto y litigio judicial vemos que las decisiones tomadas en el marco de este último generaron una serie de efectos instrumentales (Rodriguez Garavito y Rodriguez Franco, 2010) en el procesamiento de esta política. El efecto más inmediato fue que el dictado de la medida cautelar, y su posterior confirmación en diciembre de 2012, frenó por unos meses el comienzo de la obra. Este tiempo ganado sirvió también para que los trabajadores que se oponían al proyecto generaran mayores consensos dentro del hospital, habilitando procesos de diálogo e instancias de debate sobre qué usos destinarle a ese predio, en el marco de la readecuación del sistema de salud mental prevista en las leyes nacional y de la ciudad.

En este sentido, un grupo de organizaciones, colectivos, entidades académicas, arquitectos, profesionales y trabajadores de la salud ${ }^{43}$ constituyó una comisión que elaboró, puso en discusión y consensuó una "propuesta urbana integral" para el conjunto del predio de los hospitales. Esta propuesta se fue desarrollando desde el año 2010 y finalmente se presentó como proyecto de ley (Expediente №3834-P-2016) en la Legislatura porteña a fines de 2016 con el nombre de "Nodo de Promoción de la Salud-Barracas" (NPS-B).

Definido como una "propuesta urbana para tiempos post-manicomiales" ${ }^{44}$, el NPS-B propone la rezonificación del polígono completo donde funcionan los hospitales y una serie de reparcelamientos para llevar a cabo un proyecto urbano que combine tres áreas programáticas: a) una correspondiente a la gestión y abordaje de la salud pública orientada a la prevención,

43 La Comisión Impulsora del NPS-B está integrada por las siguientes organizaciones, instituciones y personas: Cooperanza, Agrupación La Cueva, Encuentro Nacional de Prácticas Comunitarias en Salud, La Puerta Centro de Salud Arte y Pensamiento, Ático (Cooperativa de Trabajo en Salud Mental), Ático ImplicArte, Taller Libre de Proyecto Social (FADU-UBA),), Grupo Mente Activa, Primera Escuela de Psicología Social E. Pichón Riviere, Raúl Camino (Médico Psiquiatra Director de la experiencia Comunidad Terapéutica en Federal), Alfredo Grande (Médico Psiquiatra y Psicoanalista Creador de la Cooperativa El Ático y Secretario organizador del encuentro de acciones desmanicomializadoras), Vicente Zito Lema (Psicólogo Social, Abogado, Escritor, Dramaturgo, Defensor de los Derechos Humanos y Decano de la Universidad de los Trabajadores), Héctor Fenoglio (Psicoanalista Director del Centro de Salud La Puerta), Oscar Ciancio (Militante por la salud), Hernan Chocrón (Militante por la Salud), Carlos Barral (Psicólogo Social), Sergio Gagliano (Arquitecto, Docente, Investigador FADU-UBA), Yamila Maita (Arquitecta), Ana Clara Sampaolesi (Arquitecta), Laura Cutufia (Arquitecta), Aldo Guzman (Arquitecto), Pablo Curra (Arquitecto), y Pablo Francisco (Arquitecto). El Equipo Técnico Social que desarrolló el anteproyecto y los aspectos técnicos y legales del proyecto de ley está conformado por: Arq. Sergio Gagliano/Hernán Chocrón/Arqta. Yamila Maita/Arqta. Laura Cutufia/Arqta. Ana Clara Sampaolesi/Arq. Aldo Guzmán/Arq. Pablo Curra/Arq. Pablo Francisco.

${ }^{44}$ Folleto de presentación del NPS-B, año 2016. 
atención y promoción de la salud; b) una de equipamiento educativo y cultural "de carácter público y estatal"; c) una destinada a un nuevo Parque Público Urbano incorporando espacios verdes e infraestructura pública para deportes, educación, recreación, etc. Entre los dispositivos previstos por el proyecto, se incluyen espacios de práctica y formación artística, de capacitación a nuevos profesionales de la salud mental, talleres productivos, emprendimientos, lugares de trabajo para la integración laboral de personas en tratamiento, entre otras propuestas.

Por otro lado, la doble condición del grupo de trabajadores y del grupo de legisladores como actores intra y extra judiciales -es decir, como actores en el procesamiento de la política, pero también como "parte" en el litigio- fortaleció el vínculo entre ambos, generando por ejemplo las condiciones para obtener apoyos en la Legislatura para presentar proyectos en defensa del hospital. Acuerdos que de todas formas fueron inestables y que se modificaron en función de las otras cuestiones en agenda ${ }^{45}$ (Oszlak y O'Donnell, 1981).

Otro de los efectos -en este caso simbólico (Rodriguez Garavito y Rodriguez Franco, 2010)- que tuvo el procesamiento del litigio en el conflicto fue la legitimidad que otorgó la medida cautelar a la posición de los trabajadores. Tal como sostienen Azuela, Melé y Ugalde (2015: 4), el derecho permite legitimar posturas, es decir, "traducir en términos de derechos las reivindicaciones que sin ellos serían menos legítimas". A esto se le suma el carácter heteroconstituyente del discurso jurídico, su función de archéion, y el tipo de enunciador que se construye a lo largo de los fallos analizados, asociado a un ethos de árbitro neutral. Estas características del discurso jurídico autorizan, legitiman otros discursos que circulan y confluyen a lo largo del conflicto.

En enero de 2013 había dos medidas cautelares que impedían al GCBA avanzar con la construcción del centro cívico. Por un lado, la medida dictada por la jueza Lopez Vergara y confirmada por la Sala II en diciembre de 2012 que suspendía el decreto licitatorio de dicha obra №121/12 hasta que se cumplieran los requisitos solicitados por la Cámara. Por el otro, una

\footnotetext{
${ }^{45}$ Nos referimos a la sanción de la ley №1443 en diciembre de 2012, votada también por una parte de los legisladores que venían rechazando la medida y defendiendo a los trabajadores del Borda. Esta ley que permite subastar el edificio del Plata, hasta entonces sede de varias dependencias del ejecutivo local, era clave para la realización del proyecto del centro cívico dado que los recursos obtenidos por la venta de este inmueble se destinarían a financiar la obra de la nueva sede gubernamental. La aprobación de esta ley fue producto de un acuerdo entre los bloques de legisladores del PRO y del Frente para la Victoria (FPV), que incluía la aprobación de tres proyectos del PRO, la venta del edificio del Plata y dos proyectos vinculados a la conformación del Centro de Transferencias de Cargas Sur en Villa Lugano; y dos iniciativas del bloque kirchnerista que buscaban la rezonificación de terrenos desafectados del uso ferroviario en Pompeya y Palermo para habilitar allí la generación de desarrollos inmobiliarios que incluyeran en parte la construcción de viviendas a través del Plan Pro.Cre.Ar.
} 
medida cautelar autosatisfactiva -establecida por la jueza de turno Elena Liberatori en enero de 2013- que exigía la reapertura del taller protegido 19.

En febrero de 2013, dos nuevas sentencias de la jueza de primera instancia Andrea Danas (del 8 y del 19 de ese mes) levantaron ambas medidas cautelares; por un lado, por considerar que el GCBA ya había cumplido los requisitos ordenados por la Sala II (expedientes №45.258 y №45.995) y, por el otro, por entender que el taller protegido 19 ya se encontraba funcionando en otro lugar, lo que tornaba a la causa "abstracta" (expediente №G17-2013/1). Ambas decisiones fueron apeladas por los demandantes, lo que motivó la intervención de la Sala II, cuyos jueces ordenaron realizar un reconocimiento judicial en la nueva sede del taller protegido 19 para el día 24 de abril de 2013.

Ante esta situación en el litigio, el GCBA se reposicionó y el 26 de abril de 2013 a las 6hs las empresas adjudicatarias de la obra, custodiadas por la Policía Metropolitana, ingresaron al predio y demolieron el taller protegido 19. El ejecutivo local, con intervención de distintas unidades -Ministerio de Salud, Ministerio de Desarrollo Urbano y Ministerio de Seguridadadoptó una nueva posición y, omitiendo la legitimidad otorgada por el derecho, previamente referida, hizo uso de la fuerza. La Policía Metropolitana desplegó una fuerte represión que incluyó disparos con balas de goma, gases lacrimógenos y golpes. Hubo cerca de 50 heridos, entre pacientes, enfermeros, legisladores, periodistas y efectivos policiales; y ocho detenidos. Se trata de un cambio en la toma de posición del GCBA que pasó del intento por buscar consensos y de litigar para obtener una medida judicial a su favor, al ejercicio de la coerción.

En el dinámico vínculo entre conflicto y litigio, este último fue influyendo en el curso de acción de la política urbana, llevando el compás del conflicto, legitimando las tomas de posición de unos y otros actores. Pero también el desarrollo del conflicto -particularmente, las estrategias y recursos movilizados por los actores por fuera del campo jurídico- incidió en el devenir del litigio y sus sucesivas redefiniciones. Después de que el GCBA demolió el taller protegido 19 y reprimió dentro del Hospital Borda, los operadores jurídicos se vieron obligados también a redefinir su posición. Al episodio violento dentro de un hospital público, le siguieron una serie de pronunciamientos, decisiones judiciales, nuevas argumentaciones y definiciones en el marco del litigio judicial.

A partir de ese momento, se puso en discusión si las medidas cautelares -levantadas en primera instancia, pero apeladas por los demandantes- estaban vigentes o no. Hubo posiciones encontradas tanto entre los legisladores opositores y funcionarios del GCBA -que se pusieron de manifiesto en las interpelaciones realizadas en la Legislatura porteña a los ex Ministros de 
Seguridad y justicia, Guillermo Montenegro, y de Desarrollo Urbano, Daniel Chaín- como en las diversas interpretaciones que hicieron los jueces de la Sala II y del TSJ.

El mismo día de la represión, el 26 de abril de 2013, la Sala II confirmó que ambas medidas cautelares (expedientes №45.258, №45.995 y G17-2013/1) se encontraban vigentes y ordenó al GCBA frenar cualquier obra en el predio donde se ubicaba el taller 19 demolido. Además, multó a los entonces Jefe de Gobierno, Mauricio Macri, Ministro de Desarrollo Urbano, Daniel Chain, y al Procurador, Julio Conte Grand, argumentando que "el proceder adoptado por la demandada viola las prácticas habituales de actuación en el marco del proceso conforme al deber de lealtad, probidad y buena $\mathrm{fe}^{\prime \prime 46}$ dado que dos días antes se había llevado adelante la inspección ocular y que el tribunal todavía no había resuelto al respecto.

A partir de acá los expedientes se desdoblaron. Mientras que la causa G17-2013/1 en relación a la medida cautelar autosatisfactoria por el funcionamiento del taller protegido 19 y las multas ordenadas por la Sala II a los funcionarios del GCBA tuvo sentencia definitiva por parte del TSJ en diciembre de 2015; los expedientes relacionados con la suspensión del decreto 121/12 (№45.258 y №45.995) continúan en instancia probatoria en el juzgado №9 de la jueza Andrea Danas.

Con respecto al primer caso, el TSJ revocó -con el voto en disidencia de la jueza Alicia Ruiz- tanto las multas puestas a los funcionarios del GCBA como la medida cautelar autosatisfactiva que obligaba al ejecutivo local a poner en funcionamiento el taller 19. Entre los argumentos de los cuatro jueces que así votaron, se destaca que el hecho de que el GCBA hubiera creado nuevas instalaciones para el taller 19 implicaba la puesta en funcionamiento del mismo y, por lo tanto, la demolición del antiguo taller no implicaba un incumplimiento de la medida cautelar. Nuevamente aparecen aquí las indeterminaciones del derecho que habilitan lecturas e interpretaciones contrapuestas por parte de los jueces, según tengan concepciones más amplias o restringidas sobre el derecho y sobre la capacidad de control que tiene el poder judicial sobre las políticas públicas.

En abril de 2015, el GCBA mudó parte de su sede administrativa al edificio construido originalmente para el Banco Ciudad, en el barrio contiguo de Parque Patricios. Posteriormente, en enero de 2016 completó la "mudanza al sur" con el traslado de las otras dependencias de gobierno al edificio remodelado de la ex Fábrica Canale, frente al Parque Lezama, dentro del Distrito de las Artes (ver mapa 1). Sin embargo, la persistencia del proyecto en el presupuesto

\footnotetext{
${ }^{46}$ Cámara de Apelaciones en lo CAyT, Sala II, expte NoG17-2013/1, resolución del 26/04/2013, pp. 2.
} 
de la ciudad ${ }^{47}$, sumado al lento pero progresivo avance en el desarrollo de los distritos especializados ubicados en los alrededores de este predio disputado, abre ciertos interrogantes sobre lo que puede ocurrir cuando se resuelva el litigio judicial.

Como mencionamos previamente, la causa principal se encuentra en instancia probatoria y la medida cautelar que suspende el decreto licitatorio del centro cívico №121/12 está vigente "hasta tanto se dicte sentencia definitiva en autos o se dé cumplimiento con los recaudos procedimentales establecidos (...), lo que ocurra primero" ${ }^{48}$. Según nos comentó la Defensora de Cámara involucrada en el litigio, la Dra. Mariana Pucciarello, al no ampliarse la causa con nuevos argumentos -más allá de los problemas técnicos- y como el tratamiento del expediente está siendo lento, en su opinión, es posible que cuando llegue el momento de la sentencia definitiva, la "cuestión de fondo" -es decir, la construcción del centro cívico en dicho lugar- se torne "abstracta". Esto significa que no se puede resolver sobre eso porque los argumentos -aquellos problemas técnicos que dieron lugar a la medida cautelar- ya no se encuentran vigentes. Si esto sucediera, el GCBA tendría habilitado el camino -al menos a nivel judicial- para continuar con el desarrollo del distrito gubernamental o con otros proyectos, como el polo de neurociencias ${ }^{49}$, en el polígono de los hospitales.

\section{COMENTARIOS FINALES}

A lo largo de este artículo reflexionamos sobre las articulaciones entre el procesamiento de una política pública urbana, el conflicto suscitado a partir de su implementación y el litigio, como una de sus dimensiones. Esto habilitó complejizar la mirada sobre el rol del Estado en el

\footnotetext{
${ }^{47}$ En los presupuestos de 2016 y 2017 del Ministerio de Desarrollo Urbano observamos que continuaba vigente el programa "Nuevo Distrito Gubernamental", con una asignación superior a 155 y 160 millones de pesos respectivamente. La descripción del programa resulta por lo menos ambigua. Por un lado, se enumera una serie de obras destinadas a completar el traslado de las sedes administrativas al sur de la ciudad, pero por el otro se seguía sosteniendo que "la iniciación de esta obra (en referencia a la construcción de los edificios del distrito gubernamental) se encuentra a la espera del levantamiento de la medida cautelar que impide su ejecución" (Jurisdicción 30 del Ministerio de Desarrollo Urbano y Transporte, Ley de Presupuesto 2016 №5495/2015, página 21).

${ }^{48}$ Cámara de Apelaciones en lo CAyT, Sala II, expte. №45.995, resolución del 28/12/2012, pp. 22.

${ }^{49}$ En el proyecto original de presupuesto 2017 que presentó el poder ejecutivo había una asignación presupuestaria de 650 millones de pesos para la creación de un Polo de Neurociencias. Así, en el Plan General de Acción y Gobierno 2017-2019 se hacía referencia al plan de refuncionalización de los hospitales psiquiátricos "ampliando el enfoque de los pacientes hacia la óptica más integradora e innovadora de las neurociencias" (GCBA, 2017: s/n). Como producto de negociaciones en la Legislatura y de la movilización de organizaciones referentes de la salud, el texto final del presupuesto 2017 no refiere a esto. Sin embargo, la insistencia en la reconversión de los hospitales, en el marco de debate sobre el sistema de salud mental, da cuenta de que el destino de este polígono de 40 hectáreas es aún incierto.
} 
procesamiento de la política, considerando los tres poderes que lo conforman y las tensiones entre ellos. El análisis de los argumentos desplegados por los operadores judiciales en las distintas demandas y sentencias; y el modo en que fueron tematizados -cada vez- el conflicto y el predio en cuestión nos permitió advertir que, al ingresar al campo del derecho, se produjo una separación entre el procesamiento de la política pública, el conflicto y el litigio. Por un lado, la política pública se presenta como una solución al "deterioro de la zona sur", especialmente de ese predio del barrio de Barracas y su disponibilidad a partir de la obligación de reconvertir el sistema de salud mental. Por el otro, el conflicto suscitado a partir de la implementación de la política puso de relieve una disputa por el uso de un espacio público vinculado a la atención de la salud mental. Por su parte, en el litigio, primó la cuestión acerca de la conservación del patrimonio cultural e histórico. Si bien en los expedientes se incorporaron argumentos vinculados al derecho a la salud y a la readecuación del sistema de salud, finalmente el argumento que resultó potente para la obtención de la medida cautelar fue la protección patrimonial.

El conflicto siempre se redefine cuando es llevado al campo del derecho, sin embargo creemos que no es casual que esta reelaboración haya estado relacionada con argumentos patrimoniales. Como señalamos, la cuestión del patrimonio ha cobrado una gran relevancia durante las últimas décadas en la agenda pública. Esto posibilitó la conformación de una unidad específica, dentro de la estructura del poder judicial de la ciudad, para intervenir en litigios donde se pone en juego la conservación del patrimonio. En un contexto en el que las estructuras de oportunidades políticas en relación al activismo judicial se han reducido, la intervención de operadores jurídicos de carácter progresista en esta unidad de patrimonio constituyó una puerta de acceso a la justicia para los actores que se opusieron al distrito gubernamental. De esta forma, el hecho de que esta UET sobre patrimonio urbano haya preparado esta demanda influyó en los términos en que se redefinió del conflicto.

Al igual que los actores en el procesamiento de la política, los operadores jurídicos han desplegado una serie de estrategias para ganar tiempo en el curso del litigio. Esto es posible, como vimos, gracias a las propias indeterminaciones del derecho, que habilitan lecturas contrapuestas por parte de los magistrados y múltiples recursos procesales que permiten demorar o acelerar las distintas etapas del litigio.

Por otro lado, entender la judicialización como una de las arenas por donde transcurre el conflicto a raíz de la implementación de una política pública, habilita el estudio del dinámico vínculo entre conflicto y litigio. Así, advertimos que las decisiones tomadas en el marco de este 
último tuvieron una serie de efectos (Rodriguez Garavito y Rodriguez Franco, 2010) en el procesamiento de esta política y en el desarrollo del conflicto. El efecto más inmediato fue que el dictado de la medida cautelar, y su posterior confirmación en diciembre de 2012, frenó por unos meses el comienzo de la obra. Este tiempo ganado sirvió también para que los trabajadores que se oponían al proyecto generaran mayores consensos dentro del hospital, habilitando procesos de diálogo e instancias de debate sobre qué usos destinarle a ese predio, en el marco de la readecuación del sistema de salud mental prevista en las leyes nacional y de la ciudad. Otro de los efectos fue la legitimidad que otorgó la medida cautelar a la posición de los trabajadores, en tanto que el derecho permite legitimar posturas (Azuela, Melé y Ugalde, 2015). A esto se le suma el carácter heteroconstituyente del discurso jurídico, su función de archéion, y el tipo de enunciador que se construye a lo largo de los fallos analizados, asociado a un ethos de árbitro neutral. Estas características del discurso jurídico autorizan, legitiman otros discursos que circulan y confluyen a lo largo del conflicto.

De este modo, el desarrollo del litigio fue incidiendo en el curso de acción de la política, llevando el compás del conflicto, legitimando las tomas de posición de unos y otros actores. Pero advertimos también que el desarrollo del conflicto -particularmente, las estrategias y recursos movilizados por los actores por fuera del campo jurídico- incidió en el devenir del litigio y sus sucesivas redefiniciones. Esto es así porque, tal como plantea Cuellar (2014), el derecho moldea pero a la vez es moldeado, se trata de un ida y vuelta en el que la fuerza reguladora del derecho es permeada y construida socialmente.

Por último, queremos destacar que si bien reelaborar el conflicto en términos de la conservación del patrimonio resultó productivo para frenar -con una medida cautelar- la construcción del distrito gubernamental y así ganar tiempo; paradójicamente esta misma redefinición -al no ampliarse con otros argumentos- podría habilitar que el proyecto siga adelante. Aquí, entonces, los argumentos técnicos encuentran sus limitaciones. De todas formas, dado que la judicialización -como dijimos- es una de las dimensiones de este conflicto, habrá que ver cómo se reposicionan los actores, qué nuevos recursos movilizan ante tal escenario y cómo esto afecta el procesamiento de esta política que permanece aún abierta. 


\section{REFERENCIAS BIBLIOGRÁFICAS}

ABRAMOVICH, Víctor y PAUTASSI, Laura. La revisión judicial de las políticas sociales. Estudio de casos. Buenos Aires: Ediciones El Puerto, 2010.

AMOSSY, Ruth. Lo plausible y lo evidente: doxa, interdiscurso, tópicos. L’argumentation dans le discours. Discours politique, littérature d 'idées, fiction (pp. 1-25). París: Nathan, 2000.

ANGENOT, Marc. El discurso social: problemática de conjunto. El discurso social. México: Siglo XXI, 1989, ed. 2010.

AZUELA, Antonio, MELÉ, Patrice y UGALDE, Vicente. Conflits de proximité et rapport ( $\mathrm{s}$ ) au ( $\mathrm{x}$ ) droit ( s ). Développement Durable et Territoires, 6(1), 0-16, 2015.

AZUELA. Antonio. "Introducción". En Azuela y Cancino (coords), Jueces y conflictos urbanos en América Latina. Ciudad de México: Procuraduría Ambiental y de Ordenamiento Territorial del Distrito Federal, 2014.

BERCOVICH, Luciana et al. "Desde el barrio hasta el juicio, construcción comunitaria, incidencia institucional y litigio para la efectividad del derecho a la vivienda en la Ciudad de Buenos Aires. En Bercovich, L y Maurino, G (coords), Los derechos sociales en la Gran Buenos Aires, Buenos Aires: Eudeba, 2013.

BOURDIEU, Pierre. El sentido práctico. Buenos Aires: Siglo XXI, 1980, ed 2007.

CHARAUDEAU, Patrick y MAINGUENEAU, Dominique (Dirs.). Diccionario de análisis del discurso. Buenos Aires: Nueva Visión, 2002, ed 2005.

COSACOV, Natalia. Usos del suelo y judicialización en Buenos Aires. En Azuela y Cancino (coords), Jueces y conflictos urbanos en América Latina. Ciudad de México: Procuraduría Ambiental y de Ordenamiento Territorial del Distrito Federal, 2014. 
CUELLAR VÁZQUEZ, Angélica. La práctica judicial vista desde la sociología. Hacia la construcción del campo jurídico. En Azuela y Cancino (coords), Jueces y conflictos urbanos en América Latina. Ciudad de México: Procuraduría Ambiental y de Ordenamiento Territorial del Distrito Federal, 2014.

DELAMATA, Gabriela. Una década de activismo judicial en las villas de Buenos Aires, Revista Dereito \& Práxis, Vol 7, №14, 2016, pp. 567-587, Río de Janeiro, 2016.

DIAZ PARRA, Ibán. Gentrificación y clase social. La producción del gentrificador. Sevilla, Departamento de Geografía Humana, Universidad de Sevilla, 2004.

DIAZ PARRA, Ibán. La gentrificación en la cambiante estructura socioespacial de la ciudad. Geo Crítica. Cuadernos Críticos de Geografía Humana, Universidad de Barcelona, 2013. Disponible en: http://www.ub.edu/geocrit/b3w-1030.htm

DI VIRGILIO, Mercedes y GUEVARA, Tomás. Gentrificación liderada por el Estado y empresarialismo urbano en la Ciudad Autónoma de Buenos Aires. Revista Estudios Sociales Contemporáneos, 11, 12-23, 2014.

FOUCAULT, Michael. La arqueología del saber. Buenos Aires: Siglo XXI, 1969, ed 2002.

GARGARELLA, Roberto y MAURINO, Gustavo. Vivir en la calle. El derecho a la vivienda en la jurisprudencia del TSJC. En Lecciones y Ensayos, №89, Buenos Aires, 2010.

GOICOECHEA, María Eugenia. Distritos Creativos en el Sur de la Ciudad de Buenos Aires (20082015). Renovación urbana y nuevas lógicas de segregación. Vol 1. Tesis doctorial inédita, Universidad de Buenos Aires, 2016.

GONZALEZ BRACCO, Mercedes. Vecinos en defensa del patrimonio urbano en la Ciudad de

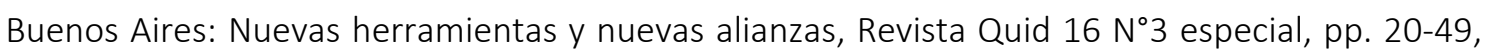
2013.

GUEVATA, Tomás. Políticas habitacionales y procesos de producción del hábitat en la Ciudad de 
Buenos Aires. El caso de La Boca. Tesis de maestría inédita, Facultad de Ciencias Sociales, Universidad de Buenos Aires, 2010.

HARVEY, David. A teoría marxista do Estado. En Harvey, David A producao capitalista do espaco. San Pablo Annablume, 1970, ed 2006.

HERZER, Hilda. Acerca de la gentrificación. Herzer (comp.) Con el corazón mirando al sur. Buenos Aires: Espacio, 2008.

MAINGUENEAU, Dominique y COSSUTTA, Frederic. L'analyse des Discourse constituans. Langages, (117), 112-125, 1995.

MAINGUENEAU, Dominique. Términos clave del análisis del discurso. Buenos Aires: Nueva Visión, 1996, ed 2008.

MALDIDIER, D. La inquietud del discurso. Un trayecto en la historia del análisis del discurso. El trabajo de Michel Pêcheux, Signo \& Seña 1, pp. 201-213, 1990, ed. 1992.

MELÉ, Patrice. Conflits urbains pour la protection de la nature dans une métropole mexicaine. En Patrice Mellé, Corinne Larrue y Muriel Rosemberg Conflits et territoires. Presses universitaires Francois Rabelais, 2003, edición 2007. Disponible en: http://halshs.archivesouvertes.fr/halshs-00005676/en/\%5Cnhttp://en.scientificcommons.org/27196049

MELÉ, Patrice. ¿Qué producen los conflictos urbanos? En Carrión y Erazo (Coord) El derecho a la ciudad en América Latina. Visiones desde la política. (pp. 127-158). México: UNAM, Coordinación de Humanidades, PUEC, CIALC, IDRC/CRD, 2016.

MONTERO, Ana Soledad. El análisis francés del discurso y el abordaje de las voces ajenas: interdiscurso, polifonía, heterogeneidad y topos. En Canales, M. (comp.) Escucha de la escucha. Análisis e interpretación en la investigación cualitativa (pp. 247-273). Santiago de Chile: LOMFACSO, 2014. 
O'DONNELL, Guillermo. Apuntes para una Teoría del Estado. En Oscar Oszlak (comp.), Teoría de la burocracia estatal: enfoques críticos. Buenos Aires: Paidós, 1984.

OSZLAK, Oscar. Notas críticas para una teoría de la burocracia estatal, Documento CENDES/G.E. CLACSO. Vol 8, 1977. Buenos Aires, 1977.

OSZLAK, Oscar. Falsos dilemas: micro-macro, teoría - caso, cuantitativo-cualitativo. En La trastienda de la investigación social (pp. 1-24). Buenos Aires: Editorial Manantial, 2011.

OSZLAK, Oscar y O'DONNELL, Guillermo. Estado y políticas estatales en América Latina: hacia una estrategia de investigación. Cedes, (4), 98-128, 1981.

RODRIGUEZ, María Carla y DI VIRGILIO, Mercedes. Ciudad de Buenos Aires: políticas urbanas neoliberales, transformaciones socio-territoriales y hábitat popular. Revista de Direito Da Cidade, 6(2), 323-347, 2014. Disponible en: https://doi.org/10.12957/rdc.2016.19115

PUCCIARELlO, Mariana. El área no penal del Ministerio Público Fiscal de la Ciudad de Buenos Aires. Sup. Administrativo La Ley, 15, Buenos Aires, 2011.

RODRÍGUEZ, María Carla, BAÑUELOS, Carla y MERA, Gabriela. Intervención - no intervención: ciudad y políticas públicas en el proceso de renovación del Área Sur de la Ciudad de Buenos Aires. En Herzer (organizadora) Con el corazón mirando al sur. Transformaciones en el sur de la ciudad de Buenos Aires. Buenos Aires: Espacio Editorial, 2008.

RODRÍGUEZ, María Carla y DI VIRGILIO, Mercedes. Coordenadas para el análisis de las políticas urbanas: un enfoque territorial. En Rodriguez y Di Virgilio (comps). Caleidoscopio de las políticas territoriales Un rompecabezas para armar. Buenos Aires: Prometeo, 2011.

RODRIGUEZ GARAVITO y RODRIGUEZ FRANCO Cortes y cambio social. Cómo la Corte Constitucional transformó el desplazamiento forzado en Colombia. Bogotá: Centro de Estudios de Derecho, Justicia y Sociedad, Dejusticia, 2010. 
SABSAY, Daniel. El acceso a la vivienda digna en un fallo de la Corte Suprema de Justicia de la Nación. En Revista Pensar en Derecho, Buenos Aires: Eudeba Editorial Universitaria, 2012.

VON DER DUNK et al. Defining a typology if peri-urban land-use conflicts- a case studynfrom Switzerland. Landscape and Urban Planing, núm. 101, pp. 149-156, 2011.

Otros documentos

CESLESM. Informe de seguimiento, 2010.

CESLESM. Informe de seguimiento, 2012.

CESLESM. Informe de seguimiento bianual, 2015.

CONGRESO DE LA NACIÓN ARGENTINA. Ley Nacional de Salud Mental. Ley №26.657, 2010.

LCBA. Ley de Salud Mental de la ciudad de Buenos Aires. Ley №448, 2000.

LCBA. Proyecto de ley Expte. №3834-P-2016. "Nodo de Promoción de la Salud-Barracas" (NPSB), 2016.

\section{Fallos judiciales}

Acción de amparo colectivo en la causa "Naddeo, María Elena y otros contra GCBA sobre amparo (art. 14 CCABA), expte. №45.258, agosto de 2012.

Cámara de Apelaciones en lo CAyT, Sala II, expte. №45.995, resolución del 28/12/2012; Juzgado de feria de primera instancia en lo CAyT, expte. G17-2013/1, resolución del 16/01/2013 [MP Elena Liberatori].

Cámara de Apelaciones en lo CAyT, Sala II, expte №G17-2013/1, resolución del 26/04/2013. 
Cámara de Apelaciones en lo CAyT, Sala II, exptes. №45.258, №45.995, №G17-2013/1, resolución del 19/09/2013.

Juzgado de primera instancia en lo CAyT №5, expte №45.258, resolución del 05/09/2012 [MP Fabiana Schafrik].

Juzgado de primera instancia en lo CAyT №2, expte. №45.995, resolución del 27/10/2012, [MP Patricia Lopez de Vergara].

Juzgado de primera instancia en lo CAyT №9, expte. 45.258, resolución del 19/02/2013 [MP Andrea Danas].

Resolución №299/12 de la Defensoría General.

TSJ, expte. G17-2013/1, resolución del 16/12/2015.

Trabalho enviado em 23 de maio de 2018

Aceito em 08 de agosto de 2018 